\title{
Influence of Shear-Thinning Blood Rheology on the Laminar-Turbulent Transition over a Backward Facing Step
}

\author{
Nathaniel S. Kelly ${ }^{\circledR}$, Harinderjit S. Gill ${ }^{\circledR}$, Andrew N. Cookson ${ }^{\circledR}$ and Katharine H. Fraser *(D) \\ Department of Mechanical Engineering, University of Bath, Bath BA2 7AY, UK; N.Kelly@bath.ac.uk (N.S.K.); \\ R.Gill@bath.ac.uk (H.S.G.); A.N.Cookson@bath.ac.uk (A.N.C.) \\ * Correspondence: K.H.Fraser@bath.ac.uk
}

Received: 6 March 2020; Accepted: 15 April 2020; Published: 23 April 2020

check for updates

\begin{abstract}
Cardiovascular diseases are the leading cause of death globally and there is an unmet need for effective, safer blood-contacting devices, including valves, stents and artificial hearts. In these, recirculation regions promote thrombosis, triggering mechanical failure, neurological dysfunction and infarctions. Transitional flow over a backward facing step is an idealised model of these flow conditions; the aim was to understand the impact of non-Newtonian blood rheology on modelling this flow. Flow simulations of shear-thinning and Newtonian fluids were compared for Reynolds numbers $(R e)$ covering the comprehensive range of laminar, transitional and turbulent flow for the first time. Both unsteady Reynolds Averaged Navier-Stokes ( $k-\omega$ SST) and Smagorinsky Large Eddy Simulations (LES) were assessed; only LES correctly predicted trends in the recirculation zone length for all Re. Turbulent-transition was assessed by several criteria, revealing a complex picture. Instantaneous turbulent parameters, such as velocity, indicated delayed transition: $R e=1600$ versus $R e=2000$, for Newtonian and shear-thinning transitions, respectively. Conversely, when using a Re defined on spatially averaged viscosity, the shear-thinning model transitioned below the Newtonian. However, recirculation zone length, a mean flow parameter, did not indicate any difference in the transitional Re between the two. This work shows a shear-thinning rheology can explain the delayed transition for whole blood seen in published experimental data, but this delay is not the full story. The results show that, to accurately model transitional blood flow, and so enable the design of advanced cardiovascular devices, it is essential to incorporate the shear-thinning rheology, and to explicitly model the turbulent eddies.
\end{abstract}

Keywords: blood; rheology; transition; Newtonian; shear-thinning; non-Newtonian; Large Eddy Simulation (LES); Unsteady Reynolds Average Navier-Stokes (URANS)

\section{Introduction}

While blood flow in the healthy cardiovascular system is predominantly laminar, insight into the transition from laminar to turbulent blood flow is vital for understanding the development of cardiovascular diseases and for the design of blood-contacting devices (for example: ventricular assist devices, mechanical heart valves and stents). Occluded vessels, such as those seen in arterial stenoses, can trigger laminar-turbulent transition, leading to the development of recirculating flow regions. Furthermore, viscous shearing due to fluid dynamic stresses along the endothelial monolayer of blood vessels can cause alterations to the function and shape of the cells [1]. This has been closely linked to the promotion and further development of atherosclerosis through mechanotransduction [2]. These stenotic regions can facilitate the aggregation of platelets and create recirculation zones, providing an optimal environment for coagulation [3]. Turbulent blood flow can also occur in healthy 
patients with no pathological diseases [4,5]. 4D MRI flow data indicated an increase in turbulent kinetic energy (TKE) of $73 \%$ in the aorta of older patients compared to younger patients which was determined to be related to area dilation of the aorta due to vascular ageing. For cardiovascular devices, turbulent flows can lead to damage of blood components in the form of mechanical haemolysis and thrombus formation [6]. In mechanical haemolysis, the rupturing of red blood cells (RBCs) due to fluid stresses and artificial surfaces can cause anaemia and kidney failure [7].

To understand how to minimise the effects of blood damage, it is essential to consider blood at a fundamental level. The contribution of RBCs and proteins affects the rheology, with blood exhibiting shear-thinning properties [8]. These properties develop due to unique characteristics that RBCs possess, i.e., deformability and their interaction with proteins. At low shear rates $\left(\dot{\gamma}<100 \mathrm{~s}^{-1}\right)$, plasma proteins such as fibrinogen and globulins cause RBCs to aggregate and form into stacks known as rouleaux [9]. When the shear rate is increased $\left(\dot{\gamma}>100 \mathrm{~s}^{-1}\right)$, these aggregates break down in a reversible process, where the RBCs elongate in the direction of flow due to deformability, and the viscosity becomes constant with shear rate i.e., Newtonian. In addition to the shear-thinning properties, there have been numerous discussions on other rheological properties that whole blood possesses-viscoelasticity, yield stress, and thixotropy [10-13]. The importance of these rheological properties in disease development and design of cardiovascular devices remains an active area of research.

Investigations into the critical Reynolds number $\left(R e_{c r}\right)$ of whole blood have been performed by several authors $[14,15]$. More recently, it has been shown that in the laminar-turbulent transition regime there are differences in the critical Reynolds number between Newtonian blood analogues (water-glycerine) and whole blood [16]. Biswas et al. [16] found that, in a straight pipe, whole blood transitioned at $R e_{c r}=2806$, whereas the Newtonian analog had $R e_{c r}=2316$, when using the TKE as a method for determination of $R e_{c r}$. Numerical investigations include three-dimensional direct numerical simulation (DNS) using the spectral element method of a stenosis, where three-dimensional instabilities and transition in both steady and pulsatile flow were explored [17]. Newtonian blood demonstrated a transition occurring around a $R e_{c r}=722$, with relaminarization being evident downstream of the constriction. DNS was also performed using the finite element method to explore the differences in transition to turbulence between Newtonian and shear-thinning blood (Modified-Cross model) rheologies through a stenosis [18]. Shear thinning blood showed a delay in transition with a $\operatorname{Re}_{c r}=760$, compared to a Newtonian $R e_{c r}=700$. However, the definition of viscosity had a strong influence on the determination of $R e_{c r}$, with a spatially and temporally averaged viscosity reducing the shear-thinning model to $R e_{c r}=710$, leaving no significant difference in $R e_{c r}$.

Shear-thinning fluids have been shown to demonstrate a delay in transition to turbulence [19-21]. A yield stress fluid (0.2\% Carbopol solution) and a shear-thinning fluid (Carboxymethyl Cellulose) demonstrated differences in transition, assessed using laser Doppler velocimetry (LDV) [22]. A delay was measured through detection of centreline velocity, friction factor and velocity fluctuation analysis when compared to a Newtonian fluid (Glucose syrup). In particular, the yield stress fluid exhibited transition in two stages, firstly from the laminar velocity profile, and then through the existence of turbulent spots. It has been indicated that, when evaluating transition of non-Newtonian fluids, the root mean square (RMS) of velocity fluctuations, $u^{\prime}$, provides a better indication of the onset of transition in shear-thinning fluids compared to traditional friction factor vs. Re plots for pipe flows [23]. Through DNS, it has been observed that power law fluids also demonstrate intermittency in transition to turbulence through the existence of turbulent puffs and slugs.

A backward facing step creates a flow separation similar to that of a stenosis, with both having rapid expansions resulting in shear layer separation. Additionally, due to the simple geometry, there are many applications, gas turbine combustors [24], flow around buildings [25], and biomechanical applications [26-28]. Initial experimental investigations into backward step flows of air were conducted by Armaly et al. [29] using LDV. Due to the geometry, a separation of the shear layer occurs followed by the development of flow recirculation due to an adverse pressure gradient. As Reynolds numbers 
are increased, reattachment and detachment points develop on both upper and lower walls of the geometry, with the primary recirculation zone located behind the step, the length of this zone changing with flow regime. It was observed that transitional flow begins at $R e=1200$, where the primary recirculation length reaches a peak value, with fully turbulent flow developing at $R e=6600$.

Further investigations of transitional flow in the backward facing step have been conducted both experimentally and numerically [30,31], summarised in Table 1 . The development of instabilities and three-dimensionality at the step has also been explored by means of DNS using the spectral element method [32]. Downstream of the step, wave like structures resembling Tollmein-Schlichting waves (wave formations which exist in bounded shear flows) were observed, which was shown to cause excitations of the primary separation zone. Le et al. [33] found that, for $R e=5100$, the reattachment length oscillates around a mean value $(6.28 \times$ step height $)$, with the TKE in the recirculation region similar to that in the turbulent mixing layer [33]. Many of the numerical studies conducted on the backward facing step geometry have been two-dimensional problems, which has restricted the exploration of turbulent phenomena.

The flow separation which the backward facing step flow exhibits is similar to that which exists in common cardiovascular devices such as mechanical heart valves (MHVs) and which can have a large impact on the vascular endothelium due to shear stresses [34]. A numerical study on the impact of non-Newtonian blood rheology on endothelial cell responsiveness was conducted by Choi and Barakat [28]. Simulations of both steady and pulsatile flow $50<R e<400$ showed differences in recirculation zone length, between the two rheologies, with a shorter primary recirculation zone in the shear-thinning blood rheology. A sinusoidal velocity profile at the inlet provided pulsatile flow conditions causing break-up of the recirculation zones in both models, with multiple vortices forming in the Newtonian blood model, compared to the shear-thinning.

Table 1. Backward facing step flow and reverse flow regions have been explored both experimentally and numerically by a number of authors. The majority of works reported below were a variation on Armaly et al. [29], with the flow regime, rheological properties and expansion ratio (ER) being altered. The following notation is used; L-Laminar, TR-Transitional, T-Turbulent, $R e_{D}$ - Reynolds number based on inlet height, $R e_{\delta}$ - Reynolds number based on boundary layer thickness, $R e_{h}-$ Reynolds number based on step height.

\begin{tabular}{ccccc}
\hline Author (Year) & $\begin{array}{c}\text { Numerical/ } \\
\text { Experimental }\end{array}$ & $\begin{array}{c}\text { Flow } \\
\text { Regime }\end{array}$ & $\begin{array}{c}\text { Reynolds } \\
\text { Number } \\
\text { Definition }\end{array}$ & Rheology \\
\hline Armaly et al. (1983) & Experimental \& Numerical & L-TR-T & $R e_{D}$ & Newtonian \\
\hline Driver and Seegmiller (1985) [35] & Experimental \& Numerical & $\mathrm{T}$ & $R e_{\delta}$ & Newtonian \\
\hline Le, Moin and Kim (1997) [33] & Numerical & $\mathrm{T}$ & $R e_{h}$ & Newtonian \\
\hline Gijsen, Vosse and Janssen (1998) [27] & Experimental \& Numerical & $\mathrm{L}$ & $R e_{h}$ & $\begin{array}{c}\text { Newtonian and } \\
\text { Shear thinning }\end{array}$ \\
\hline Poole and Escudier (2003) [36] & Experimental & $\mathrm{T}$ & $R e_{h}$ & Thixotropic/Shear thinning \\
\hline Poole and Escudier (2003) [37] & Experimental & $\mathrm{T}$ & $R e_{h}$ & Viscoelastic/Shear thinning \\
\hline Choi and Barakat (2005) [28] & Numerical & $\mathrm{L}$ & $R e_{D}$ & $\begin{array}{c}\text { Newtonian and } \\
\text { Shear thinning }\end{array}$ \\
\hline Barri et al. (2009) [38] & Numerical & $\mathrm{T}$ & $R e_{h}$ & Newtonian \\
\hline Schaefer, Breuer and Durst (2009) [30] & Numerical & $\mathrm{TR}$ & $R e_{D}$ & Newtonian \\
\hline Kopera et al. (2014) [39] & Numerical & $\mathrm{T}$ & $R e_{h}$ & Newtonian \\
\hline Current Work & Numerical & $\mathrm{L}-\mathrm{TR}-\mathrm{T}$ & $R e_{D}$ & $\begin{array}{c}\text { Newtonian and } \\
\text { Shear thinning }\end{array}$ \\
\hline
\end{tabular}

The behaviour of blood in the laminar-turbulent transition is not well understood. Neglecting the influence of RBCs and assuming blood to be a Newtonian fluid may cause incorrect predictions of transition. This prediction is vital for the design of safer cardiovascular devices where it is crucial to minimise blood damage. The aim of this present study was to explore the effect of blood rheology on the transition to turbulence of single phase blood. Computational fluid dynamics (CFD) using 
OpenFOAM v5 [40] was used to simulate the flow of both Newtonian blood and shear-thinning blood over a backward facing step for a range of Reynolds numbers to determine the extent to which $R e_{c r}$ for transition differs between the two rheologies. Initial simulations used Unsteady Reynolds Averaged Navier-Stokes (URANS), but these could not predict the recirculation zone lengths with sufficient accuracy. Large Eddy Simulation (LES) was then used and transition assessed from several turbulence characteristics. This study is the first to simulate backward facing step flow using LES over the whole range of $R e$ from laminar to fully turbulent flow, and hence is the first to investigate the effect of shear-thinning rheology on transition to turbulence in this geometry. These are the most comprehensive simulations of transitional flow in a backward facing step geometry to date.

\section{Methods}

\subsection{Governing Equations}

The governing Navier-Stokes equations, Equations (1) and (2), were solved using OpenFOAM v5 [40]. For an incompressible, Newtonian fluid, $\mathbf{u}$ is the velocity vector, $p$ is the pressure, and $v$ is the kinematic viscosity. Numerical simulations were performed by solving both URANS using Menter's $k-\omega$ SST turbulence model to obtain the mean flow and LES using the Smagorinsky subgrid scale (SGS) to model the small scale motions:

$$
\begin{gathered}
\nabla \cdot \mathbf{u}=0 \\
\frac{\partial \mathbf{u}}{\partial t}+\nabla \cdot(\mathbf{u u})-\nabla \cdot(\nu \nabla \mathbf{u})=-\nabla p
\end{gathered}
$$

\subsubsection{Menter's $k-\omega$ SST Model}

A variation on the standard $k-\omega$ model, Menter's SST $k-\omega$ model is a two equation model, more suited to adverse pressure gradients [41]. This hybrid model uses a $k-\omega$ model in the near wall region, while in the fully turbulent region switches to a standard $k-\varepsilon$ model. The first transport equation, Equation (3), corresponds to the TKE $k$ and the second, Equation (4), being the transport of specific rate of dissipation $\omega$. In the following equations, $P_{k}$ is the production term for $k, v_{t}$ is the turbulent kinematic viscosity and $S_{i j}$ is the mean strain rate of the flow and $S=\sqrt{2 S_{i j} S_{i j}} . F_{1}$ and $F_{2}$ are blending functions and used for a smooth transition between the two models. The following model closure constants are used $\sigma_{k}=1, \sigma_{\omega}=2, \sigma_{\omega, 2}=1.17, \gamma=0.44, \beta^{*}=0.09$ :

$$
\begin{gathered}
\frac{\partial k}{\partial t}+\nabla \cdot(k \mathbf{u})=\nabla \cdot\left[\left(v+v_{t} \sigma_{k}\right) \nabla k\right]+P_{k}-\beta^{*} k \omega \\
\frac{\partial \omega}{\partial t}+\nabla \cdot(\omega \mathbf{u})=\nabla \cdot\left[\left(v+v_{t} \sigma_{\omega}\right) \nabla \omega\right]+\frac{\gamma}{v_{t}}-\beta^{*} \omega^{2}+2\left(1-F_{1}\right) \frac{\sigma_{\omega, 2}}{\omega} \frac{\partial k}{\partial x_{k}} \frac{\partial \omega}{\partial x_{k}} \\
P_{k}=\min \left(S_{i j}, 10 \beta^{*} k \omega\right) \\
v_{t}=\frac{\alpha_{1} k}{\max \left(\alpha_{1} \omega, S F_{2}\right)}
\end{gathered}
$$

\subsubsection{Smagorinsky SGS Model}

Using LES, the large scale motions containing the most energy are resolved by the mesh, while the SGS motions are modelled. This is achieved by using a low pass filter, applied to the velocity field in the form of Equation (7), to remove the small scales:

$$
\widetilde{\mathbf{u}}=\int_{-\infty}^{\infty} G\left(x, x^{\prime}\right) u\left(x^{\prime}\right) d x^{\prime}
$$


For finite volume methods, the filter function, $G\left(x, x^{\prime}\right)$ is typically a box or top hat filter function. The filtered Navier-Stokes equations are then solved by modelling the SGS tensor, for the following simulations the Smagorinsky SGS model is implemented. The turbulent viscosity $v_{S G S}$ is computed by Equation (8), where $C_{S}$ is the Smagorinsky coefficient (0.17), $\Delta$ is the filter cut-off width (cube root volume) and $S_{i j}$ is the filtered strain rate tensor Equation (9).

$$
\begin{gathered}
v_{S G S}=\left(C_{S} \Delta\right)^{2} \sqrt{2 \bar{S}_{i j} \bar{S}_{i j}} \\
\bar{S}_{i j}=\frac{1}{2}\left(\frac{\partial \bar{u}_{i}}{\partial x_{j}}+\frac{\partial \bar{u}_{j}}{\partial x_{i}}\right)
\end{gathered}
$$

\subsection{Computational Domain}

A 3D backward facing step was modelled similar to that of Armaly et al. [29]; this is shown in Figure 1. As highlighted by [30], the spanwise dimension $B$ has a large influence on the development of the recirculation zones in 3D flow. $B$ was determined in accordance with the DNS simulations of Le et al. [33]. The computational domain has the following parameters: an inlet height of $h=5.2 \mathrm{~mm}$, step height of $S=4.89 \mathrm{~mm}$, this corresponds to an expansion ratio (ER) ER $=1.98$ and a spanwise depth $B=18 \mathrm{~mm}$. The upstream and downstream and streamwise lengths are given in terms of inlet height $h$ in Figure 1.

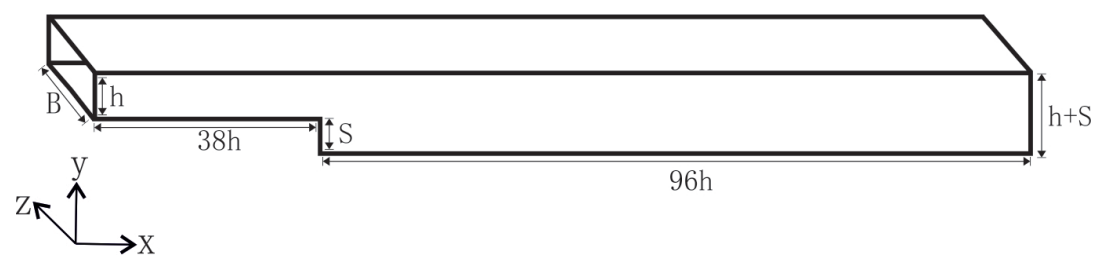

Figure 1. The backward facing step geometry studied here, with an expansion ratio of 1.98.

\subsection{Mesh Generation and Sensitivity Study}

The domain was discretized using the blockMesh utility, a multiblocks method using hexahedral cells. Local mesh refinement was implemented by altering the cell expansion ratios used along the upper and lower walls. A grid resolution study was performed on four different mesh densities-coarse, medium, fine and very fine. Table 2 shows the number of cells in streamwise $(x)$, wall-normal $(y)$ and spanwise $(z)$ directions and the mesh grading in terms of dimensionless wall distance $x^{+}, y^{+}$and $z^{+}$. The primary recirculation zone length was computed for a specified Reynolds number $R e=5000$. This was then compared to experimental data of Armaly et al. [29], in addition to DNS data of Le et al. [33] (for $R e=5100, \mathrm{ER}=1.2$ ).

Table 2. A mesh independence study was performed on four mesh densities; coarse, medium, fine, and very fine mesh. The corresponding no. of cells and dimensionless wall units $x^{+}, y^{+} z^{+}$for each mesh are shown.

\begin{tabular}{cccccc}
\hline & Mesh & No. of Cells & $x^{+}$ & $y^{+}$ & $z^{+}$ \\
\hline 1 & Coarse & $1.6 \times 10^{5}$ & 5.71 & 0.931 & 7.58 \\
2 & Medium & $1.24 \times 10^{6}$ & 3.28 & 0.464 & 4.19 \\
3 & Fine & $3.75 \times 10^{6}$ & 2.86 & 0.313 & 2.91 \\
4 & Very Fine & $6.58 \times 10^{6}$ & 2.30 & 0.270 & 2.21 \\
\hline
\end{tabular}

\subsection{Boundary Conditions}

The inflow boundary condition has a strong influence on the flow dynamics downstream of the step [30]. Experimental data indicate that the velocity profile upstream of the step is parabolic; 
however, it was shown that the Reynolds number upstream was within the transitional flow regime, concluding that the parabolic profile is not strictly valid. Schafer et al. performed simulations comparing the recirculation zones formed with different inflow conditions (parabolic vs. block profile) and studied the mesh independence. A turbulent block profile provided recirculation zones lengths in better agreement with the experimental data of Armaly et al. [29]. Under this assumption, a recycling method was implemented for the inlet velocity boundary condition. A mapped boundary condition was used whereby instantaneous computed fields of a plane downstream were mapped to the inlet, creating an infinitely long inlet section that allowed both the correct turbulent mean velocity profile and the correct turbulent velocity fluctuation to develop naturally. A Neumann boundary condition was applied to the outlet, and no slip boundaries for the upper and lower walls, with periodic flow conditions applied in the spanwise direction. The $k-\omega$ SST requires initialisation of both $k$ and $\omega$ across the domain which was achieved using Equations (10) and (11) [40]. $U$ is the inlet reference velocity and $I$ is a prescribed turbulence intensity based upon experimental data [35]. Similarly the turbulent specific rate of dissipation $\omega$ can be estimated using Equation (11), with the $C_{\mu}=0.09$ and $L$ being a reference length scale:

$$
\begin{gathered}
k=\frac{3}{2}(U I)^{2} \\
\omega=\frac{k^{0.5}}{C_{\mu} L}
\end{gathered}
$$

\subsection{Rheological Models}

Several viscosity models have been used to replicate the shear-thinning behaviour of blood. Amongst the most popular are the Power law, Carreau, Carreau-Yasuda, Powell-Eyring and Cross models [42]. In this study, we have chosen the Carreau model is used, following Choi and Barakat [28], with the same curve fitting parameters as Cho and Kensey [43]. The Carreau model follows Equation (12), with infinite shear rate viscosity $\mu_{\infty}=3.5 \mathrm{mPa}$.s, zero shear rate viscosity $\mu_{0}=0.25$ Pa.s, time constant $\lambda=25 \mathrm{~s}$, and power law index $n=0.25$ :

$$
\begin{gathered}
\mu=\mu_{\infty}+\left(\mu_{0}-\mu_{\infty}\right)\left[1+(\lambda \dot{\gamma})^{2}\right]^{\frac{(n-1)}{2}} \\
\operatorname{Re}=\frac{\rho(2 h) U}{\mu_{\infty}}
\end{gathered}
$$

It was assumed that the Newtonian model has a constant viscosity across shear rate, represented by the infinite shear viscosity $\mu_{\infty}$. The dynamic viscosity for whole blood [8], the Carreau model (a data fit of whole blood data from [8] used by [28]), and Newtonian blood data, are plotted as a function of shear rate in Figure 2. Flow was simulated for the range $50<R e<7000$ to cover the laminar, transitional and turbulent flow regimes. The Reynolds number is based upon Equation (13), with the infinite high shear rate viscosity being used, and assuming the density of blood is $\rho=1060 \mathrm{~kg} \mathrm{~m}^{-3}$. 


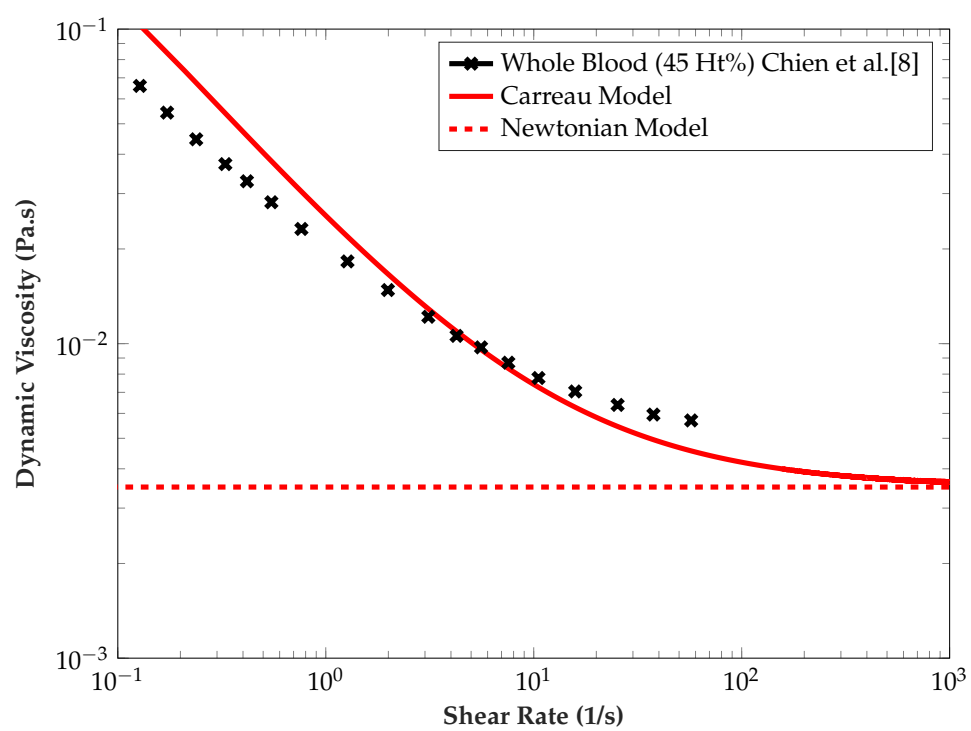

Figure 2. The Carreau model (red line) Equation (12) was used to replicate the behaviour of whole blood from Chien et al. [8] (black crosses). It was assumed that the Newtonian model had a constant viscosity equivalent to the infinite shear viscosity $\mu_{\infty}$ (red dashed line).

\subsection{Solution of Equations}

Gaussian integration discretization schemes were chosen based on the convective (second order accurate, unbounded), diffusive (second order accurate, unbounded), pressure (second order, unbounded) and temporal (second order, implicit) terms in the governing equations. The PISO algorithm was used for pressure-velocity coupling. A timestep of $1 \times 10^{-5} \mathrm{~s}$ was used.

\subsection{Parallel Processing}

Simulations were carried out using HPC services Balena at University of Bath [44] (2.6 GHz, 8 cores Intel Xeon E5-2650v2 series processors, and UK National Tier-2 Cirrus [45] (2.1 GHz, 18-core Intel Xeon E5-2695 series processors). The computational domain was decomposed using the decomposePar utility with the simple method (geometric decomposition by $x, y, z$ coordinates) being used. Parallelisation of the simulations was implemented using openMPI. Benchmarking was conducted, and it was found that 32 cores was the optimal core quantity for Balena, while 36 cores was suitable for Cirrus for the mesh densities used.

\subsection{Analysis of Recirculating Flow Regions}

The flow through a backward facing step generates several flow attachment and detachment points downstream. Figure 3 shows these point locations as determined by Armaly et al. [29]. An important feature of the developing recirculation zones are the changes with the spanwise direction (B). The flow fields of all simulations are both time-averaged and spatially averaged in the spanwise direction to obtain positions of detachment and reattachment. These points were measured by two different methods (also used by Le et al. [33]). Firstly, by observing the change in direction of skin friction coefficient $\left(C_{f}\right)$ distribution across the respected walls in the streamwise direction. Secondly, by finding the position where the mean flow velocity component, $U_{x}$, close to the wall, was equal to zero. For this work, we only examined the behaviour of the primary recirculation zone $\left(x_{1}\right)$, as the focus was on the transition to laminar-turbulent flow behaviour between the two rheologies. Statistical averaging of all simulations was performed using 2500 timepoints covering approximately $50 \mathrm{~h} / U_{b}$, which is 5 eddy turnovers. The eddy turnover time was found by integrating streamlines of the mean velocity field of the primary recirculation zone $x_{1}$. 


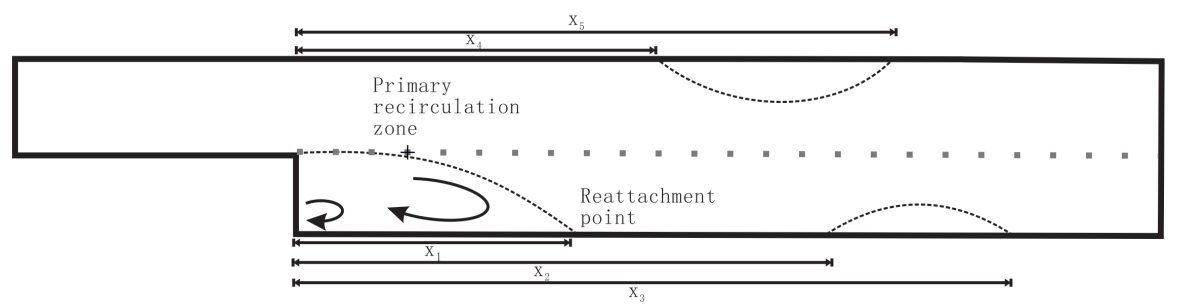

Figure 3. Flow through a backward facing step creates a number of flow attachment and detachment points downstream. The primary recirculation zone is located in front of the step with a length $x_{1}$. Two other recirculation bubbles also form on the lower wall $\left(x_{3}-x_{2}\right)$ and along the upper wall $\left(x_{5}-x_{4}\right)$. The dotted grey line corresponds to the centreline where virtual data probes were placed for monitoring velocity through time. The cross indicates the position at which instantaneous velocity signals were sampled through time (discussed in Section 3.5).

\section{Results}

\subsection{Mesh Independence Study}

The results obtained from the four meshes (Table 2) are plotted in Figure 4. The primary recirculation zone normalised by the step height $\left(x_{1} / S\right)$ was computed and used to compare the resolution of the meshes for both the $k-\omega$ SST model and the Smagorinsky SGS model. The mesh study was performed with a Reynolds number of 5000, which is still within the transitional regime. The results show that the finest grid was sufficient to simulate the flow for both turbulence models there were no significant changes in $x_{1} / S$. Comparing the primary recirculation zone lengths obtained with the fine and very fine mesh shows that the results are mesh independent within $1.32 \%$ and $0.47 \%$ with the $k-\omega$ SST model and the Smagorinsky SGS model respectively. The Smagorinsky SGS recirculation zone length is $19.1 \%$ longer than that by Armaly et al. [29].

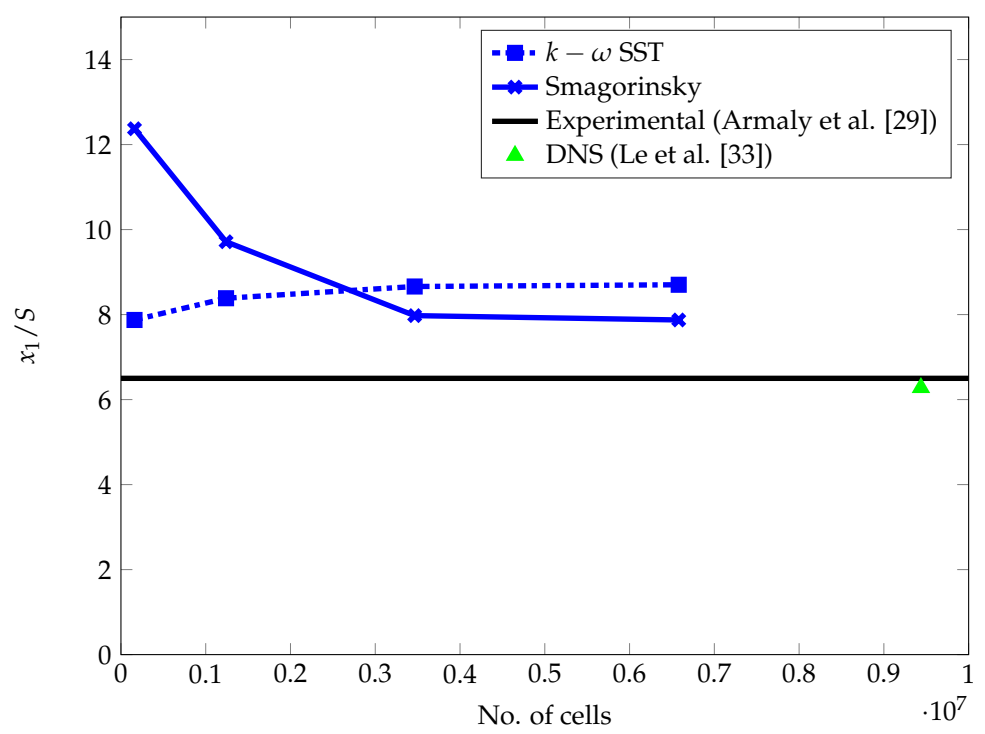

Figure 4. A mesh resolution study was performed on the four meshes outlined in Table 2. The primary recirculation zone normalised by the step height, $S,\left(x_{1} / S\right)$ was used to compare the different mesh densities.

\subsection{Validation Study}

\subsubsection{Validation of Recirculation Zone Length for Newtonian Blood Rheology}

A comparison of $x_{1} / S$ between $k-\omega$ SST, Smagorinsky and the experimental data of Armaly et al. [29] is made in Figure 5 for all $R e$ values. Our results show that the Smagorinsky 
model can predict $x_{1} / S$ with high accuracy up to a Reynolds number of a 400 . Once $R e=800$ is reached, a divergence in the increase of $x_{1} / S$ as compared with experiment is visible. 2D DNS simulations [29] also demonstrate this behaviour, but with much larger divergence. The $k-\omega$ SST model has shown that $x_{1} / S$ is difficult to predict across all flow regimes. The model fails to predict the onset of transition with high inaccuracies at $R e=1200-4000$. However, once the late transitional flow regime begins $R e>4000$, the $k-\omega$ SST model is able to predict $x_{1} / S$ with similar accuracy to the Smagorinsky model.

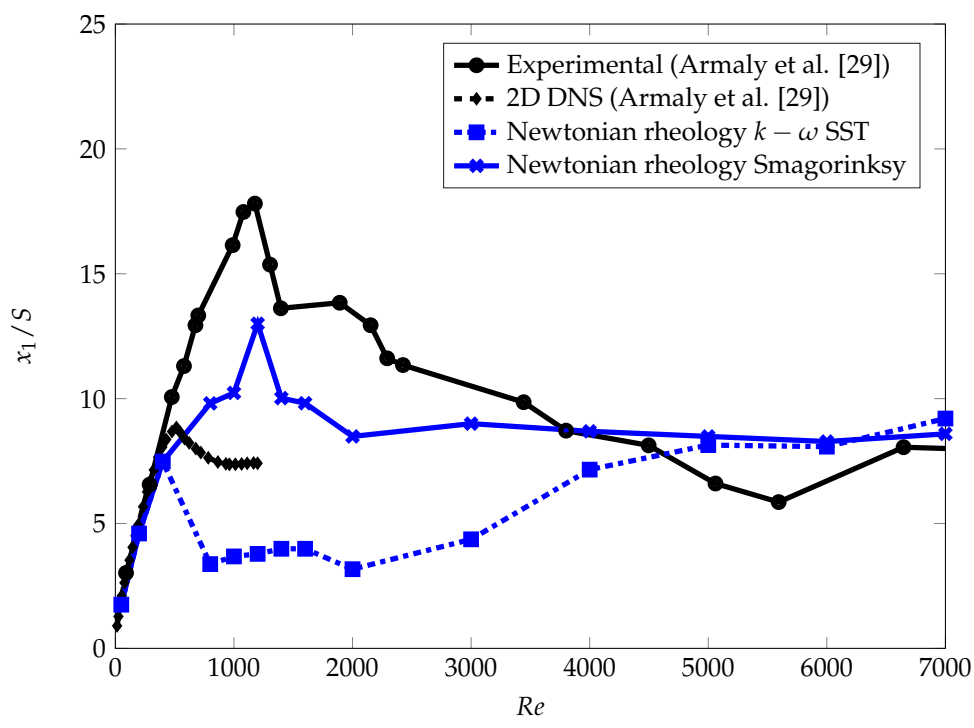

Figure 5. Time-averaged and spatially averaged primary recirculation $x_{1}$ normalised by step height $S$ of Newtonian blood rheology is plotted as a function of Reynolds number. Experimental data (black line) and 2D DNS calculation from Armaly et al. [29] are also shown.

Figure 6 shows the difference in the time average velocity magnitude between the $k-\omega$ SST and Smagorinsky models for $R e=1200,3000$ and 7000. The first difference which can be observed is at $R e=1200$, where there is a large underprediction of $x_{1} / S$ using the $k-\omega$ SST model compared to the Smagorinsky SGS model. In addition, a recirculating flow region is seen on the upper wall in the Smagorinsky SGS model, also observed by Armaly et al. [29], but not when using the $k-\omega$ SST model.

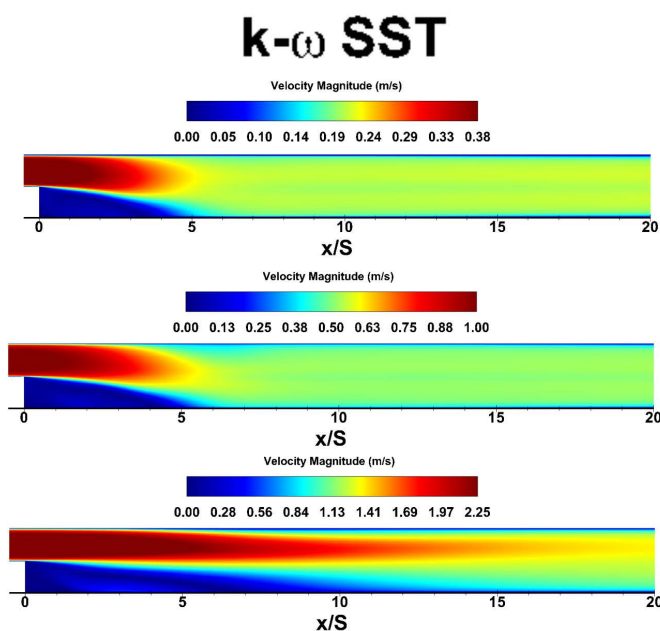

(a)

\section{Smagorinksy}

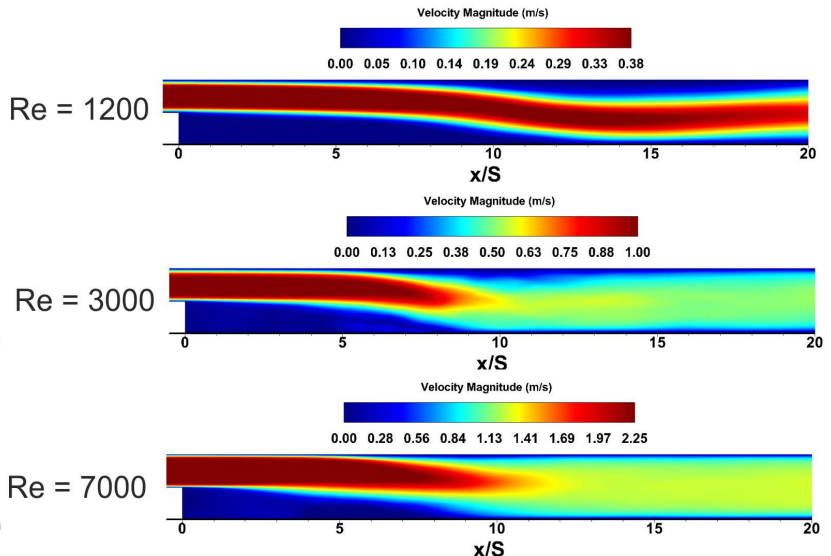

(b)

Figure 6. Time-averaged velocity magnitude contours for the $k-\omega$ SST model (a) and Smagorinsky (b) for $\operatorname{Re}=1200, \operatorname{Re}=3000$ and $\operatorname{Re}=7000$. 


\subsubsection{Validation of Recirculation Zone Length for Shear-Thinning Rheology}

To validate the impact of shear-thinning blood rheology, $x_{1} / S$ was computed for Newtonian and shear-thinning rheologies for $50<\operatorname{Re}<400$ and compared to published values in Figure 7 . The shear-thinning blood rheology exhibits a shorter recirculation zone length compared to the Newtonian rheology. This behaviour is consistent throughout the laminar flow regime; it is found that the difference at $R e=400$ is $22 \%$, which is identical to the value found by Choi and Barakat [28].

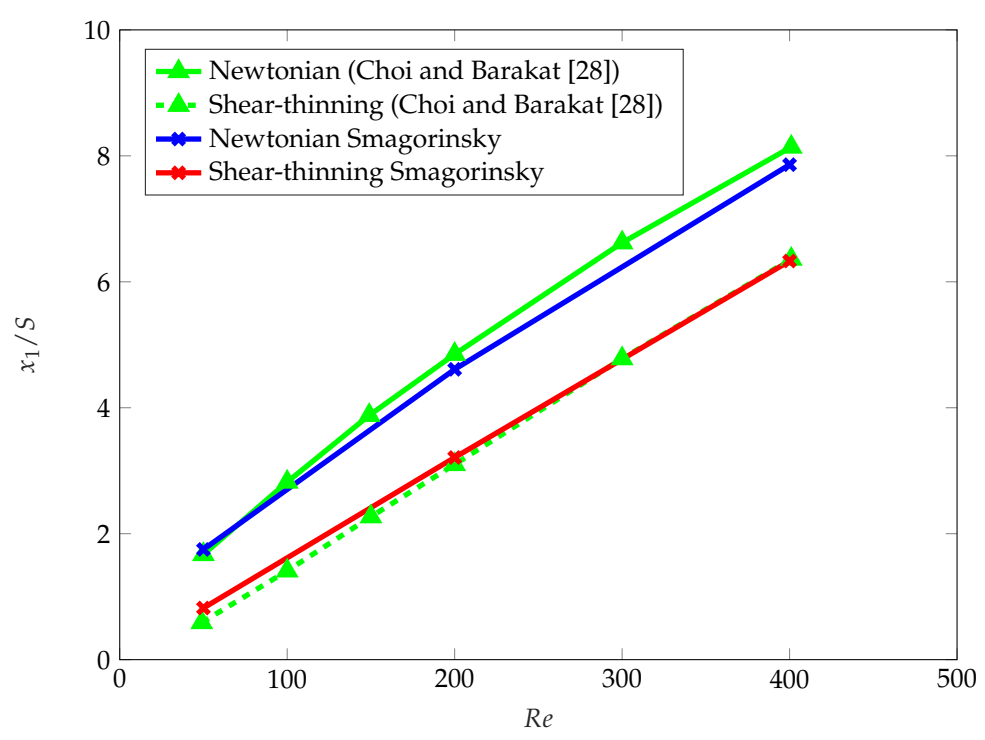

Figure 7. Time and spatially averaged primary recirculation $x_{1}$ normalised by step height $S$ for Newtonian (blue line) and shear-thinning (red line) blood rheology plotted as a function of Reynolds number. Numerical data from Choi and Barakat [28] (Newtonian-solid green line and shear-thinning-dashed green line).

\subsection{Impact of Newtonian vs. Shear-Thinning Blood Rheology on Recirculation Zone Length for All Re}

Figure 8 shows the comparison of both Newtonian and shear-thinning blood rheology and the impact on the recirculation zone length. At low $R e$, there is a significant difference in $x_{1} / S$ at $R e=800$. As $R e$ is increased further, differences between the two rheologies continue up to $R e=4000$. Beyond this, both rheologies produce very similar lengths (a difference of $2.32 \%$ ). The peak for both blood rheologies appears to occur at $R e=1200$, which Armaly et al. [29] hypothesised is the start of the transitional flow regime. Since the Smagorinsky SGS model provides a better comparison with experimental data across all flow regimes, the results in subsequent sections will be obtained using only the LES solver. 


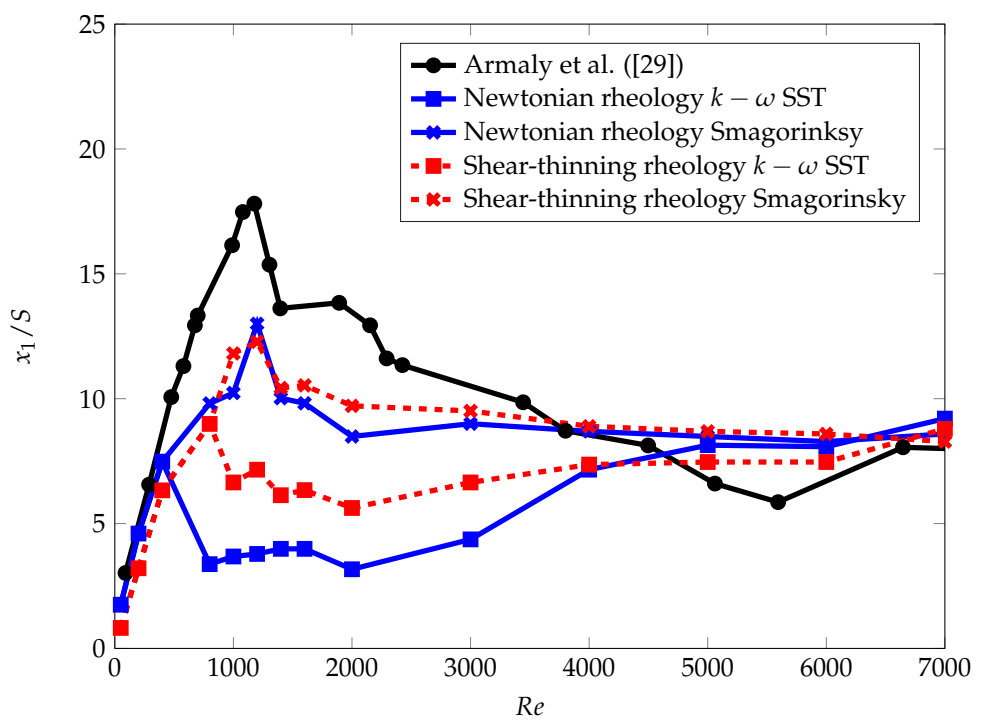

Figure 8. Time-averaged and spatially averaged primary recirculation $x_{1}$ normalised by step height $S$ for Newtonian and shear-thinning blood rheology for both $k-\omega$ SST and Smagorinsky is plotted as a function of Reynolds number. Experimental data (black line) from Armaly et al. [29] are also shown.

\subsection{Velocity and Vorticity Flow Fields}

Velocity and vorticity fields of the two blood rheologies are compared in Figures 9 and 10, respectively. No exact qualitative differences can be seen from the vorticity contour plots in terms of the vortical structures forming between the two rheologies, but other observations can be made. As Re is increased, the complex behaviour of the shear layer separation is present and vortex shedding over the step is clear. These small shear layer vortices become larger through possible merging and begin to concentrate within the same region $4 \leq x / S \leq 10$, particularly noticeable from $\operatorname{Re}=4000$ to $\operatorname{Re}=7000$. These vortices, larger in scale, then begin to break up downstream and dissipate through the domain, where lower regions of vorticity are visible. The recirculating flow regions from $R e=2000$ then begins to decrease in length as $R e$ is increased to fully turbulent flow, as shown previously in Figure 8.

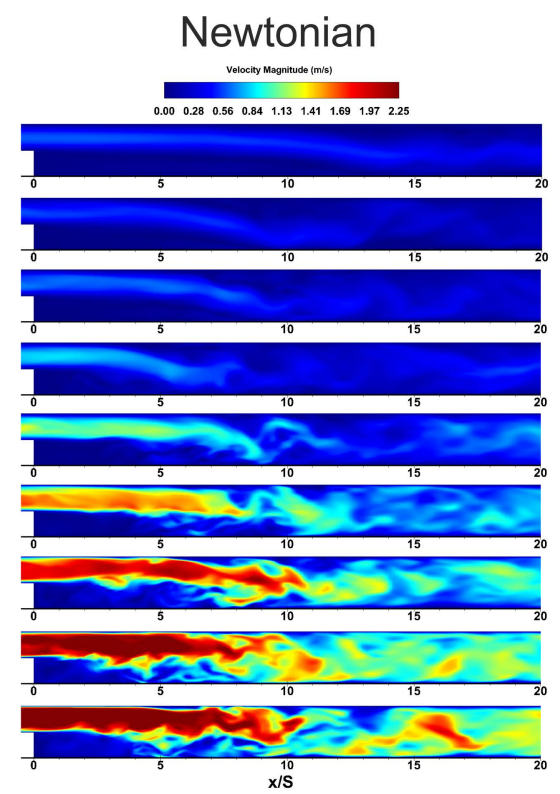

(a)

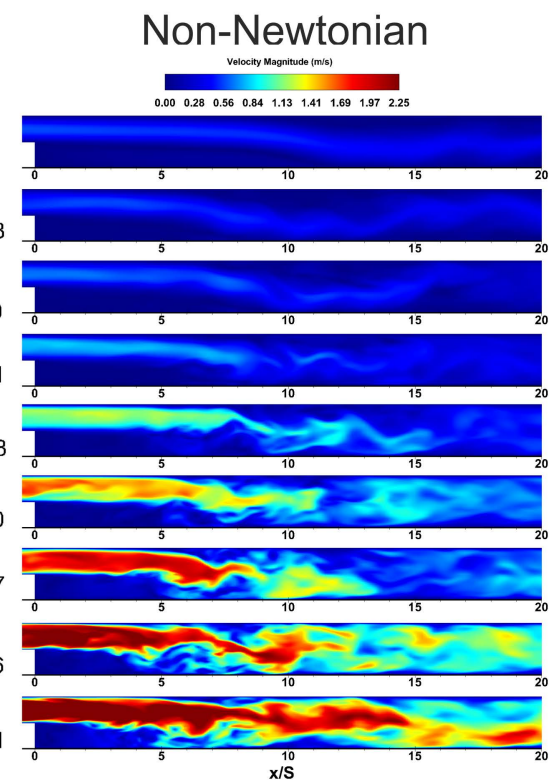

(b)

Figure 9. Instantaneous velocity magnitude contours for Newtonian blood rheology (a) and shear-thinning blood rheology (b). 


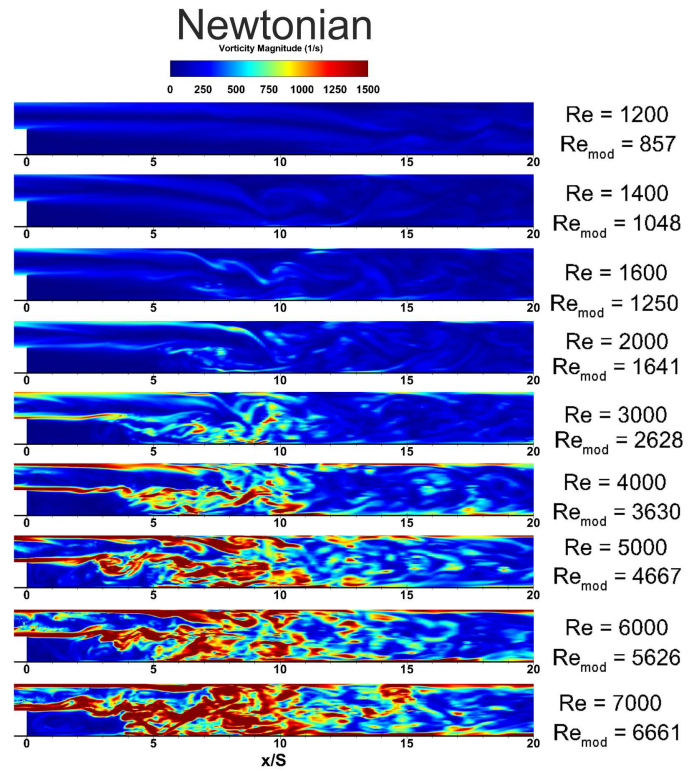

(a)

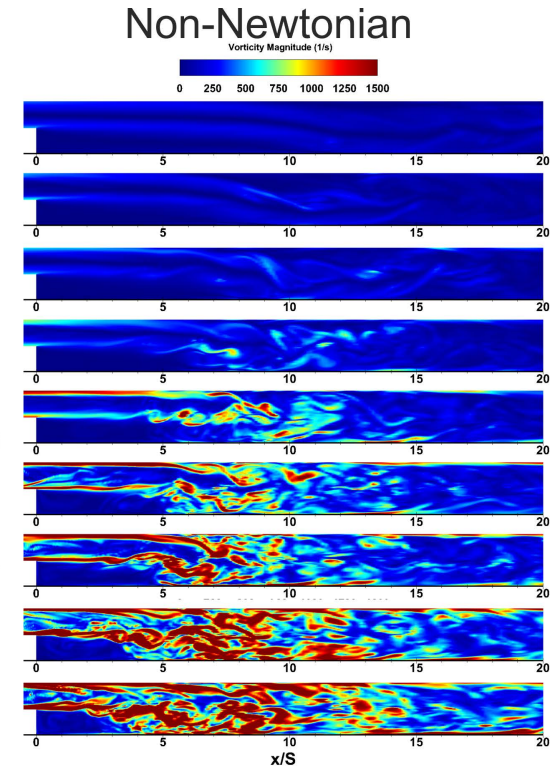

(b)

Figure 10. Instantaneous vorticity magnitude contours for Newtonian blood rheology (a) and shear-thinning blood rheology (b).

\subsection{Temporal Flow Analysis}

The laminar-turbulent transition for both rheology models was assessed by studying the fluctuations of instantaneous velocity $u$ through time as $R e$ was increased. Virtual data probes were placed in the domain downstream of the step through the centre of the channel (indicated in Figure 3) and the velocity components were recorded through time. To obtain the velocity fluctuations $u^{\prime}$, a time average of the instantaneous velocity field $u$ was obtained. The time averaged velocity field $\bar{u}$ was then subtracted from the instantaneous velocity field in order to obtain the fluctuating component. The total TKE, $k$, was calculated using Equation (15), with the turbulence intensity I computed as the TKE normalised by the bulk inlet velocity $U_{b}$, Equation (16):

$$
\begin{gathered}
u^{\prime}=u-\bar{u} \\
k=\frac{1}{2}\left(\overline{u^{\prime 2}}+\overline{v^{\prime 2}}+\overline{w^{\prime 2}}\right) \\
I=\frac{\sqrt{\frac{2}{3} k}}{U_{b}}
\end{gathered}
$$

Figure 11 shows the instantaneous velocity magnitude taken at $x / S=6.13, y / S=0.1$, $z / S=0$ (indicated with a cross on Figure 3) for both Newtonian and shear-thinning blood rheology. As expected, for low $\operatorname{Re}(1000$ and 1200), the velocity traces show that no dominant fluctuations exist for the flows. At $R e=1400$, the Newtonian model begins to show small perturbations-these are not evident in the shear-thinning model. The shear-thinning model does not begin to show any fluctuations until $R e=2000$. This behaviour shows a possible delay of $\Delta R e=400$ in the shear-thinning model. The fluctuations become more intense when $R e=3000$, where, in the Newtonian model, it can be seen that the fluctuations are intermittent through time. As $R e$ is increased to 4000 , both models show very similar fluctuations indicating that both rheologies have reached the transitional flow regime, with 7000 indicating fully turbulent velocity signals. 


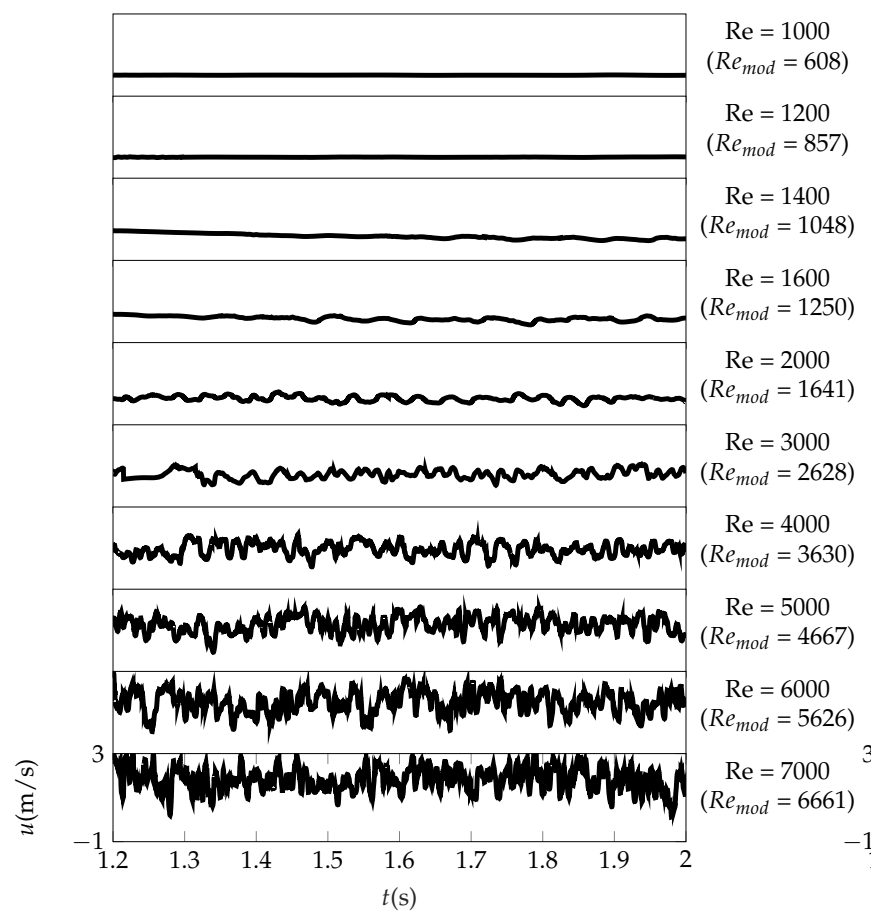

(a) Newtonian

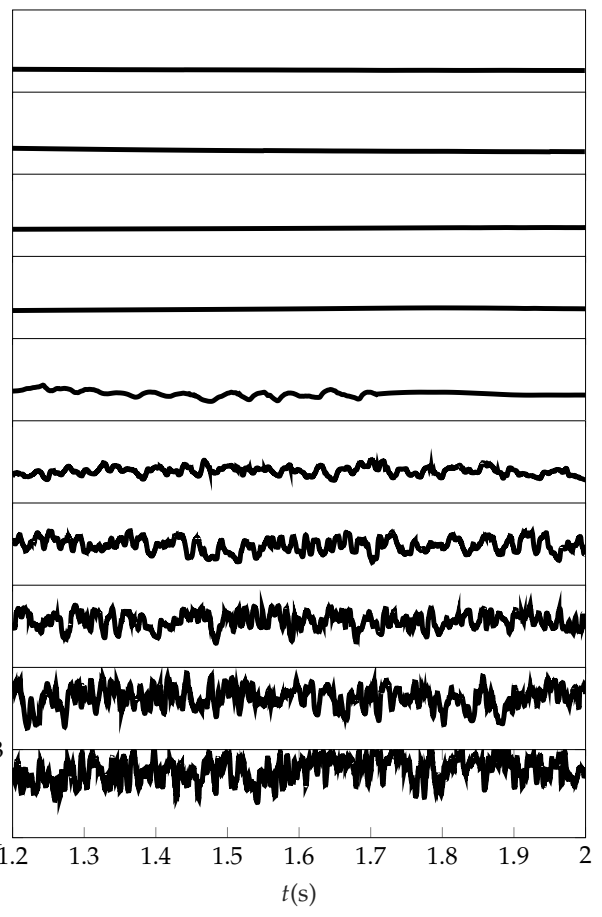

(b) Shear-Thinning

Figure 11. Monitoring of velocity magnitude through time of Newtonian blood (a) and shear-thinning blood (b) at point $x / S=6.13, y / S=0$ and $z / S=0$.

\subsubsection{Turbulence Intensity}

Contour plots of the turbulence intensity are presented in Figure 12 for each Reynolds number and both rheologies. The largest differences in turbulence intensity between the two rheologies occurred at $R e=1400$ and $R e=1600$. At these two Reynolds numbers, there were scattered regions of high turbulence intensity between $5 \leq x / S \leq 13$, which indicates transitional flow behaviour. As the Reynolds number is increased, two main regions of turbulence intensity are evident, the largest region occurs downstream of the primary recirculation zone. This region of high turbulence intensity begins to increase in streamwise length with increasing $R e$. The second region of interest is along the upper wall, where at $R e=2000$ in the Newtonian model we see the high turbulence intensity ranging from $6 \leq x / S \leq 13$. This region begins to reduce in size as $R e$ is increased; for both rheologies, this upper wall turbulence intensity reduces, and the region occurs between $7 \leq x / S \leq 10$ at $R e=7000$, suggesting fully turbulent flow. These plots shows that there are large variations in spatial distribution of the turbulent kinetic energy with each Reynolds number and between the two rheologies. 


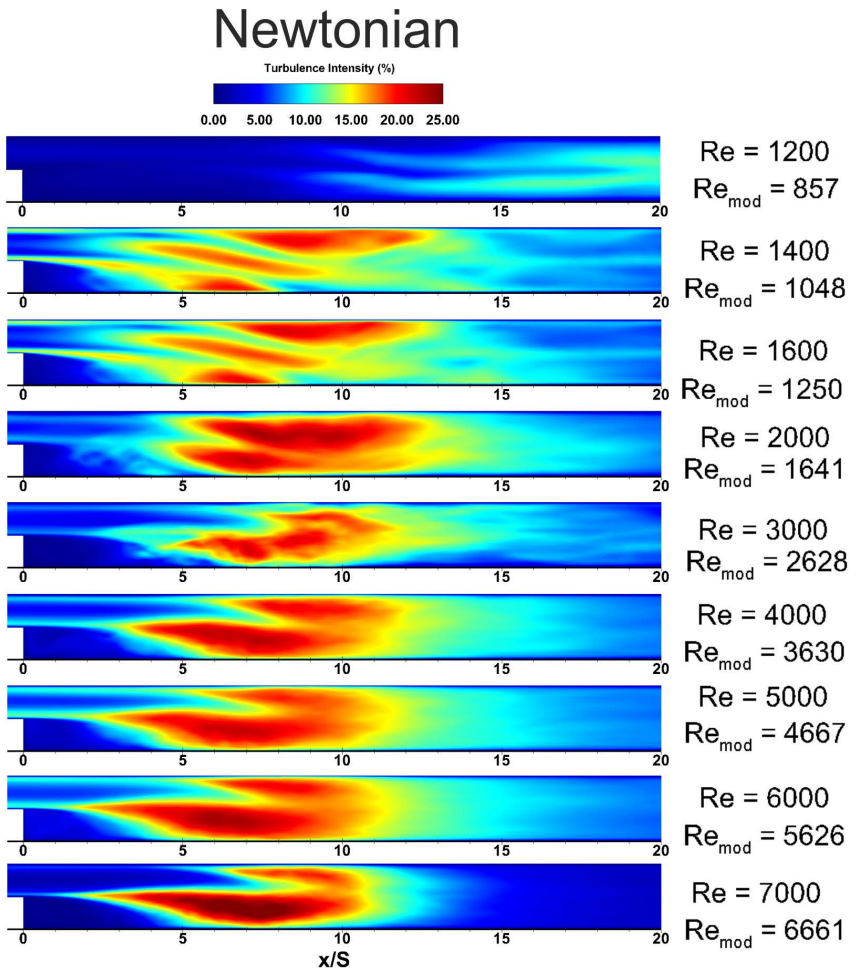

(a)

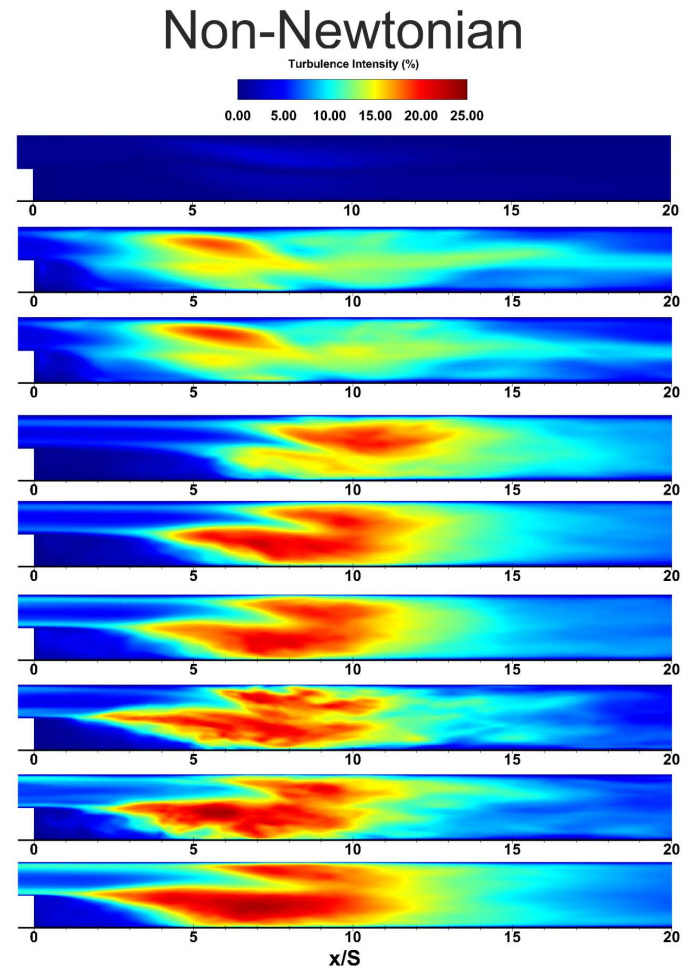

(b)

Figure 12. Turbulence intensity contour plots of each Reynolds number for Newtonian (a) and shear-thinning (b) blood rheology.

The turbulence intensity from the velocity fluctuations was computed at varying Reynolds numbers to determine $R e_{c r}$. The turbulence intensity was measured at 50 positions located $10 \mathrm{~mm}$ distance apart between $x / S=0$ and $x / S=102$, along the centreline. The mean and maximum value of the turbulence intensity were calculated for each $R e$. In Figure 13, the turbulence intensity from $0 \leq x / S \leq 15$ is plotted as a function of $R e$ for both rheologies. The results show that a peak in mean turbulence intensity along the centreline occurs at $R e=1600$ for both rheology models. Peak turbulence intensities show obvious differences between the two rheologies. The Newtonian rheology shows a sharp increase from low turbulence intensity at $R e=1600$, whilst the the shear-thinning blood rheology shows a gradual increase. In addition, $90 \%$ of the peak turbulence intensity $(19.8 \%)$ for the Newtonian rheology was reached at $R e=1600$, while the shear-thinning rheology reached this value at $R e=3000$. In general, the plots for mean turbulence intensity for both Newtonian and shear-thinning are similar. The turbulence intensity for shear-thinning is lower throughout the transitional region suggesting the non-Newtonian properties damp out some turbulence. The clear right shift for the shear-thinning plot in the region with the steepest gradient suggests a delay in $R e_{c r}$. 


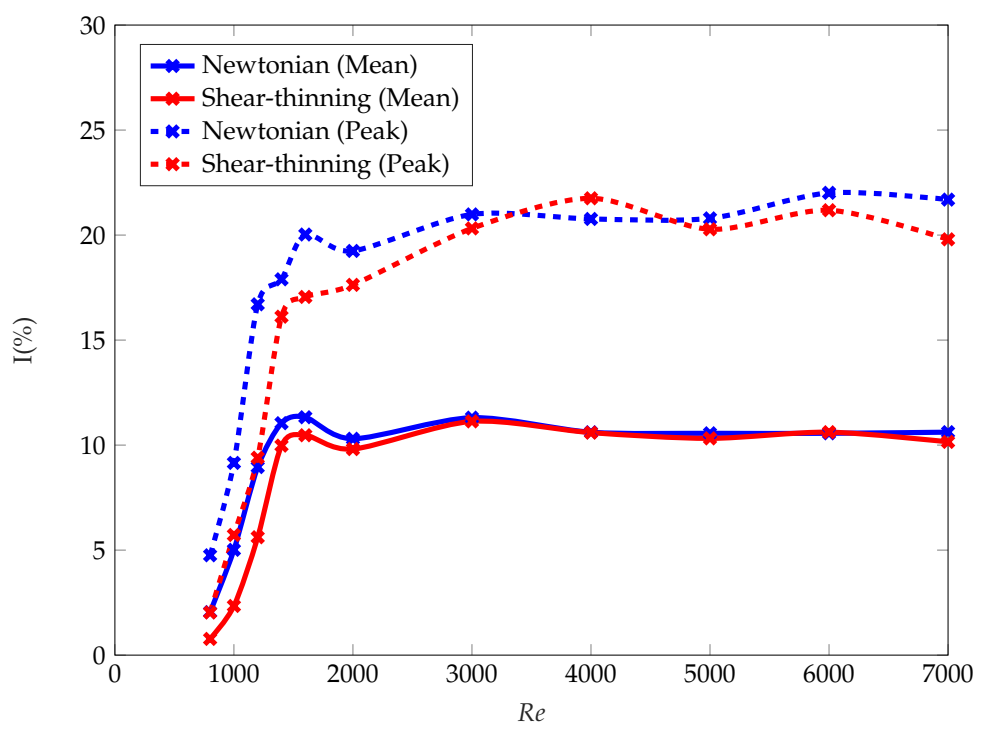

Figure 13. Turbulence intensity measured along the centreline of the domain between $0 \leq x / S \leq 15$. Newtonian and shear-thinning blood rheologies are shown for comparison. Mean (solid line) and peak (dashed line) for each Reynolds number are plotted.

\subsubsection{Turbulent Kinetic Energy Frequency Spectra}

Figure 14 shows the mean TKE spectra as function of frequency for both rheology models and all Reynolds numbers. The mean TKE was calculated by averaging the TKE from probe positions $0 \leq x / S \leq 15$. The TKE represented here is the sum of grid scales taken from the Reynolds stress tensor and SGS taken from the velocity fluctuations, $k_{t o t}=k_{G S}+k_{S G S}$. At low frequencies the TKE is low for both rheologies at $R e=1000$ and $R e=1200$. In the Newtonian model, a change in energy is observed as the frequency increases, fluctuations in energy are clear for $\operatorname{Re}=1400$ and $\operatorname{Re}=1600$, from $200 \leq f \leq 5000 \mathrm{~Hz}$. These fluctuations are contained within a smaller bandwidth for the shear-thinning model. At $R e=2000$, a visible shift of the gradient indicates an increase in turbulent kinetic energy as the Reynolds number increases for both rheologies. It can also be observed, the Newtonian rheology for each Re has higher TKE compared to the shear-thinning rheology.

The impact on the RBCs of the energy contained within the eddies was investigated by looking at specific timescales. Due to their unique shape and properties, RBCs are able to deform and regain their original configuration. The time it takes for an RBC to regain its original biconcave shape is known as the relaxation time $(\tau)$, which is approximately $100 \mathrm{~ms}$ [46]. Examining the frequencies corresponding to the relaxation time (approximately $10-30 \mathrm{~Hz}$ ), we can observe the change in energy as we increase the Reynolds number. In Figure 15, a general trend of lower energy is observed in the shear-thinning rheology compared to the Newtonian, with the biggest difference at $R e=1000$. A sharp increase is visible in both rheologies up to $R e=1600$ possibly indicating the start of transitional flow. Beyond $R e=4000$, the energy levels are very similar between both rheologies, with higher $R e$ indicating the start of turbulent flow. Given this increase in energy, the results suggest that there is enough energy to cause deformation to RBCs at low Re, however in the shear-thinning rheology RBC aggregation and deformation dynamics may suppress this behaviour to an extent. The trends here are similar to that found when analysing turbulence intensity. 


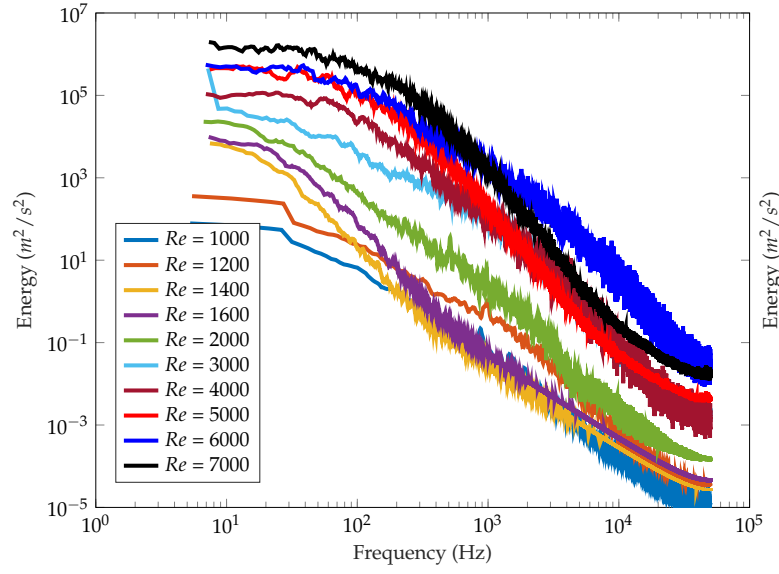

(a) Newtonian

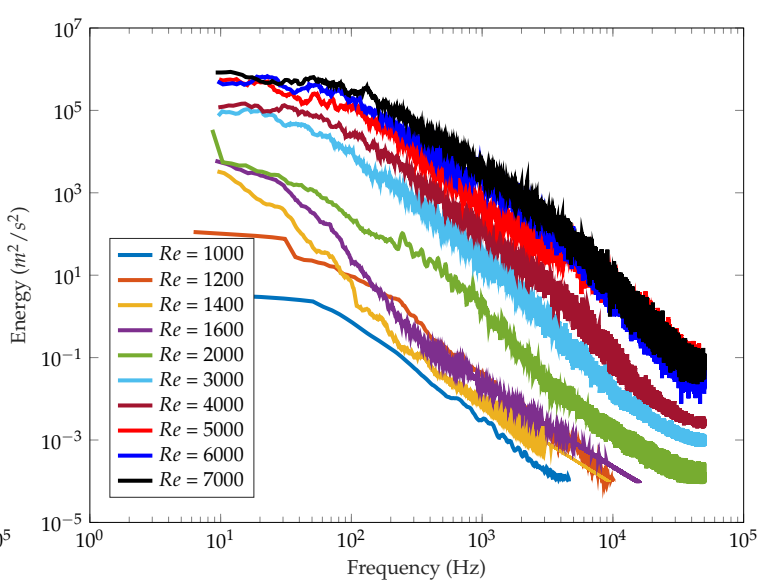

(b) Shear-Thinning

Figure 14. Mean TKE spectra for each Reynolds number. Newtonian blood rheology (a) and shear-thinning blood rheology (b).

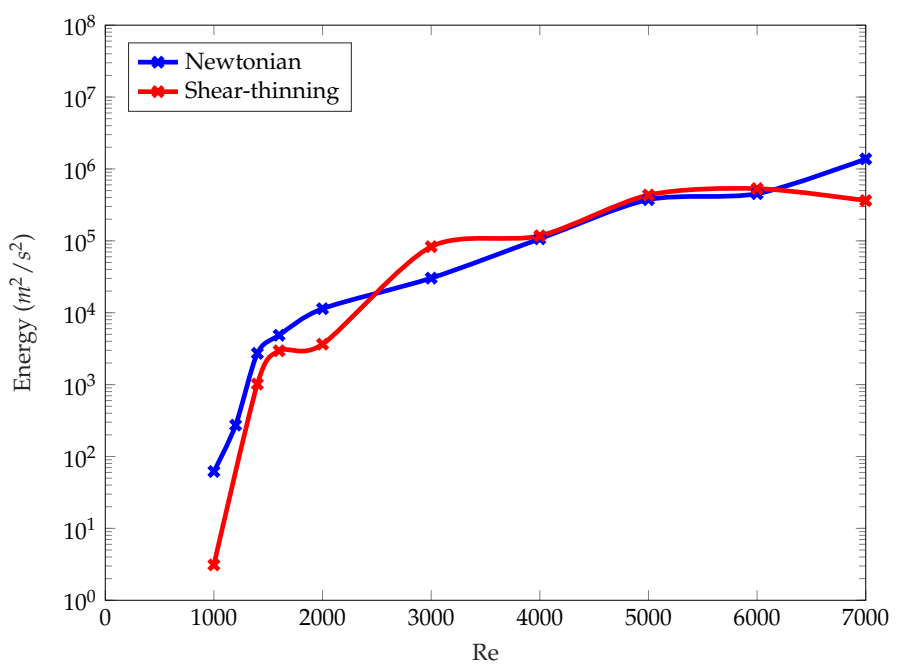

Figure 15. Mean TKE between 10-30 Hz plotted against Reynolds number for Newtonian and shear-thinning rheology.

\subsection{Impact of Shear-Thinning Blood Rheology}

Figure 16 shows the instantaneous viscosity contours for $R e=1000-7000$ for the shear-thinning model of blood. From $R e=1000$ and $R e=1200$, it is evident that low shear rate regions are located in the primary recirculating zone, in the middle of the jet, and the secondary recirculation zone. Break-up of low shear rate regions is evident at $R e=1400$, which has visibly increased by $R e=1600$. As $R e$ is increased, it can be seen that the high viscosity regions are still located downstream of the step region, with the area of these regions reducing as $R e$ increases. Large areas of the infinite shear rate viscosity are present from $R e=3000$ to $R e=7000$. 


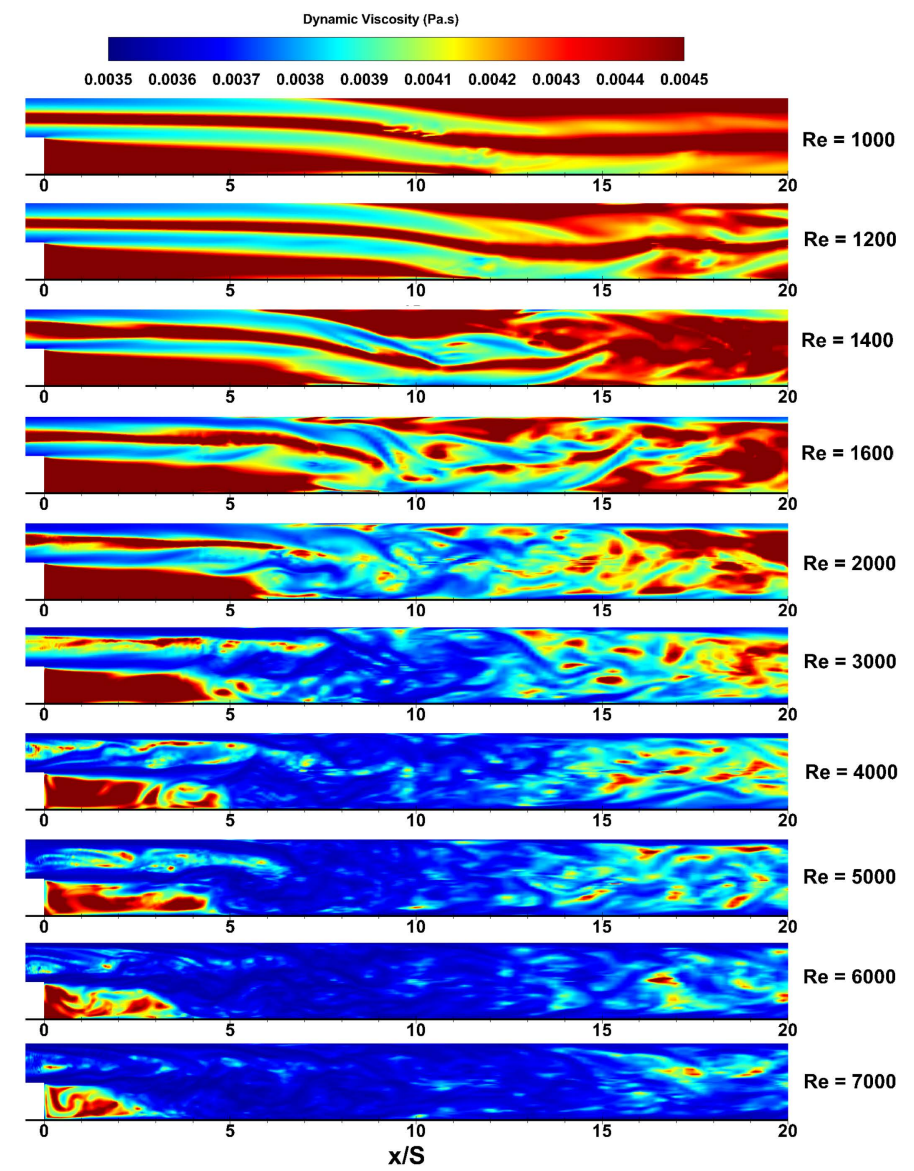

Figure 16. Instantaneous dynamic viscosity contour plots for shear-thinning blood rheology for $R e=1000-7000$.

\subsection{Effect of Shear-Thinning Viscosity on Reynolds Number}

Judging by the results of the temporal velocity analysis, $R e_{c r}$ for the Newtonian model appears to occur at $R e=1600$ compared to the shear-thinning model, where the $R e_{c r}$ is approximately at $R e=2000$. The Reynolds number defined for the simulations was based on an assumption of constant dynamic viscosity ( $3.5 \mathrm{mPas})$. However, due to the nonlinearity of the viscosity, the standard formulation of Reynolds number cannot be strictly applied. To see the effects of the shear-thinning viscosity on Reynolds number and its determination of $R e_{c r}$, a spatial average of the dynamic viscosity similar to Khan et al. [18]. The spatial average of the entire streamwise length of the domain was included and averaged in the spanwise direction.

Figure 17 shows the dynamic viscosity plotted against Reynolds number. The black line shows the change in dynamic viscosity for each Reynolds number when using the infinite high shear rate viscosity (the standard Reynolds number definition). The red line shows the dynamic viscosity behaviour using a spatially averaged viscosity within the calculation of the Reynolds number (modified Reynolds number). Using a spatially averaged value of viscosity for the Carreau model, the Reynolds number is effectively reduced at low shear rates. For example, at a dynamic viscosity of 0.0042 Pa.s, the standard Reynolds number is 2000; however, the modified Reynolds number $\left(R e_{m o d}\right)$ is only 1641. 


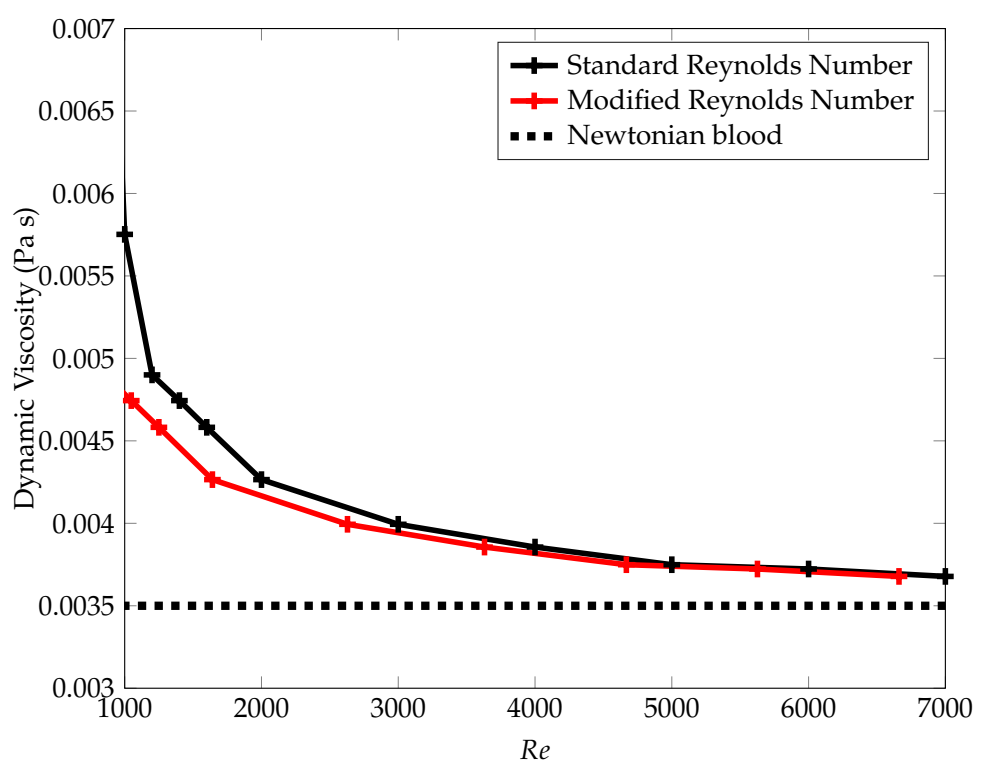

Figure 17. Computed Reynolds number based on spatially averaged viscosity with Newtonian blood viscosity (dashed line) for reference.

\section{Discussion}

In this study, the impact of shear-thinning blood rheology on the laminar-turbulent transition over a backward facing step has been explored. There are few studies that have investigated the effect of blood rheology on recirculating flow regions $[27,28]$ in a backward facing step geometry, and these have not considered the transitional flow regime. Appreciation of the transitional flow regime and the impact of non-Newtonian blood rheology is particularly important when numerical modelling is required to investigate complex cardiovascular devices and areas of vascular disease. It is also becoming necessary to evaluate the fluid dynamic stresses applied to the blood components for the quantification of blood damage with certain devices.

\subsection{Recirculation Zone Development}

The formation of recirculating and stagnant flow regions in VADs, MHVs and cardiovascular bifurcations are significant as these areas promote thrombosis. From a mechanical design perspective, this can lead to a decrease in functionality and possible malfunction; for example, centrifugal VADs such as the Heartmate II have been shown to be susceptible to thrombus formation causing the impeller to no longer function properly $[47,48]$. Again, the thrombus can cause problems for the cardiovascular system with clot transport causing occlusions and increasing the risk of myocardial infarctions and strokes. The backward facing step is an ideal geometry to explore the fundamentals of flow stagnation and recirculation.

The laminar regime was characterised by a linear increase in $x_{1} / S$ up to $R e=400$ with very good agreement with existing literature [29]. At low $\operatorname{Re}(0-400)$, the shear-thinning rheology exhibited shorter recirculation zone lengths compared to Newtonian rheology and both were in excellent agreement with published data [28]. In studies of steady stenotic flow, this was also the case as Neofytou and Drikakis [49] showed that Newtonian blood rheology exhibited larger recirculation zone compared to three other blood rheologies (Casson, Power law and Quemada). Beyond this Re, gradual deviation from the linearity can be seen, as higher Reynolds numbers (3000-7000) are reached the $x_{1} / S$ is steadily constant through the turbulent flow regime. At $R e=3000$, both rheologies showed similar lengths in $x_{1} / S$ through to the turbulent flow regime.

Comparing the two turbulence modelling methods implemented (URANS and LES) here, the Smagorinsky SGS model managed to detect transition from the peak of $x_{1} / S$ as hypothesised 
by Armaly et al. [29], whereas the $k-\omega$ SST failed to predict the length $x_{1} / S$ by a factor of 4 compared to the Smagorinsky SGS model. Using the Smagorsinky SGS model, the variation in recirculation zone length in the transitional flow regime qualitatively matched the experimental variation, but quantiatively was less accurate than in either the laminar or fully turbulent regions. Underprediction of both temporal and spatial transition has been the main disadvantage of the Smagorinsky SGS model. This has been discussed by Pal et al. [50] where they note that at laminar flow regions there is damping of flow instabilities, which results in a delay in transition to turbulence.

Differences in transition have been analysed with several turbulence models including URANS ( $k-\omega$, RNG $k-\varepsilon$, realizable $k-\varepsilon$ and $k-\omega$ SST) and LES (WALE) for poststenotic flow regions by Varghese, Frankel and Fischer [51]. They found that the $k-\omega$ SST model at low Reynolds flow performed poorly compared to DNS but similar to $k-\varepsilon$. Tan et al. [52] found that large variations in vorticity magnitudes existed between DNS, RANS hybrid $k-\varepsilon / k-\omega$ model, and various LES Smagorinsky models. Different Smagorinsky simulations were performed whereby the Smagorinsky constant $C_{s}$ was changed, with the variation of the coefficient having the largest impact on the breakdown of the jet and separation of the shear layer. This may mean that changing the value of Cs used in these simulations could provide a more realistic prediction of the reattachment point, comparable to experimental and DNS data. A more suitable solution would be to optimise the Smagorinsky constant specifically for the BFS flow, the effects of numerical dissipation would then be minimised, improving the calculation of the recirculation zone lengths. Moreover, a dynamic SGS model such as the Germano dynamic model could be used to further refine the accuracy of this model. In addition, the Smagorinsky coefficient could be locally adjusted to the flow conditions. For example, Premnath et al. [53] found that a dynamic procedure implemented within the Lattice Boltzmann method produced excellent agreement between both DNS and experimental data for recirculation zone lengths.

\subsection{Evaluation of Laminar-Turbulent Transition}

Difficulties arise when trying to compare rheologies in the transitional flow regime. The phenomena of transition to turbulence is complex, and is not instantaneous at high Re. As Armaly et al. [29] found from experimental observations, the transitional flow regime began with a peak in $x_{1} / S$. As in Armaly et al. [29], a peak reattachment length was found at $R e=1200$ for the Newtonian model, but not of the same magnitude. A possible explanation could be underestimation of turbulence intensity at the inlet due to the mapped flow boundary condition. At the start of the transitional flow regime, a decrease in $x_{1} / S$ after $R e=1200$ was found, very similar to that found by Armaly et al. [29]. However, Armaly et al. [29] found fluctuations in $x_{1} / S$ up to $R e=6600$. Our results showed that, beyond $R e=4000, x_{1} / S$ was relatively steady through to the fully turbulent flow regime, $R e=7000$. This poses the question as to whether it is possible to use a mean flow parameter such as the recirculation zone length as sole indication of the laminar-turbulent transition.

Turbulent statistics of temporal and spatial changes in the flow were not performed by Armaly et al. [29], therefore identifying $R e=1200$ as the start of transition may be debatable. For our simulations, transitional flow was analysed by (1) monitoring velocity fluctuations through time (2) measurement of the turbulence intensity (3) determination of the energy scales within the flow (4) qualitative assessment of the velocity and vorticity field. Figure 11 demonstrates the velocity through time at $x / S=6.13, y / S=0$ and $z / S=0$ for both the Newtonian and shear-thinning rheologies. These traces through time show no dominant fluctuations at low Reynolds numbers $R e=1000$ and $R e=1200$ for both rheologies; however, by $R e=1400$ and $R e=1600$, the Newtonian model exhibits small perturbations, which are not evident in the shear-thinning model. The shear-thinning model begins to show fluctuations at $R e=2000$, similar to that at $R e=1600$. Once $R e=3000$, both models can be viewed as having similar trace "intensities" with the largest perturbations existing at $R e=$ 6000 and $R e=7000$, indicating fully turbulent flow. From these observations, for the Newtonian model $R e_{c r}=1600$, while, for the shear-thinning model, $R e_{c r}=2000$, indicating a delay of 400 . 
Determination of $R e_{c r}$ by Biswas et al. [16] was defined by three main features: velocity signals through time, profile shape index and turbulent kinetic energy. From these, they found that $R e_{c r}$ was delayed by approximately $20 \%$; compared to our results, we see that from Figure 11 that $R e_{c r}$ in the shear-thinning model is delayed by $R e=400$ (from $R e=1600$ to $R e=2000$ ) giving a delay of $28 \%$.

As indicated by Peixinho et al. [22], the RMS of velocity fluctuations is a more sensitive method for detecting transition. Figure 13 used the RMS of the velocity fluctuations to compute the turbulent intensity along the centreline of the domain as a way of comparing the two blood rheologies. Mean turbulence intensity shows very similar behaviour between the two rheologies, with the $R e_{c r}=1600$, with identical trends from low to high turbulence intensity. Using the peak values of turbulence intensity as an indication for transition, the Newtonian model is observed to transition at $R e=1600$, while for the shear-thinning model an increase from low turbulence intensity occurs at $R e=3000$. Beyond this Reynolds number, the turbulence intensity is relatively constant. Using LES, it is possible to obtain qualitative data on turbulence intensity and its spatial distribution through the domain in Figure 12. The shear-thinning rheology shows smaller areas of high turbulence intensity than that of the Newtonian rheology, particularly at $R e=1400$ and $R e=1600$ i.e., where $R e_{c r}$ should occur. Similar regions and magnitudes of high turbulence intensity are present in between $R e=3000$ and $R e=4000$, indicating that $R e_{c r}$ has been reached. As the Reynolds number is increased from $R e=3000$ up to $R e=7000$, the greatest turbulence intensity is between $5 \leq x / S \leq 10$. These contours show that measurement of turbulence intensity in different regions of the domain may indicate a different trend in the turbulence intensity as seen in Figure 13.

The TKE spectra provides useful information about the turbulent structures which are present in the flow as we move into the turbulent flow regime. An average of the TKE spectra from $0 \leq x / S \leq 15$ of the instantaneous velocity traces found through the centreline of the domain is given in Figure 14a,b for Newtonian and shear-thinning rheologies, respectively. The most noticeable differences between the two rheologies are the steeper gradients occurring in the Newtonian results at lower Re compared to the shear-thinning rheology. This could suggest shear-thinning properties damping out the turbulent fluctuations resulting in lower turbulent kinetic energy but higher dissipation. Rahgozar and Rival [54] observed this experimentally, finding that a xanthan gum blood analog resulted in higher TKE dissipation compared to Newtonian blood analog, with suggestions that larger eddies have a shorter lifetime, hence smaller length scales. This poses the question as to whether the viscoelasticity of RBCs is the more dominant role in observations of delay in $R e_{c r}$ for whole blood experiments. Simulations were run up to $R e=7000$, however criteria for assessing whether this is fully turbulent were not performed. There are some indications of the inertial subrange corresponding to Kolmogorov theory, but higher Re simulations need to be performed to confirm this.

An estimation of how the eddies within the flow relate to the relaxation time of RBCs is given in Figure 15. An abrupt increase in TKE from $10 \leq f \leq 30 \mathrm{~Hz}$ is visible for both rheologies between $R e=1000$ and $R e=1600$, with the main difference in the amount of energy at $R e=1000$ and $R e=$ 1200. As the Reynolds number is increased to 4000, steady increases in behaviour were observed with identical TKE values for both rheologies. A critical Reynolds number cannot be fully determined by this criteria, however, these results allow us to explore the rheological impact that turbulent kinetic energy could have on RBCs with increasing $R$. The results show that there is sufficient TKE from at the lowest $R e$ to deform RBCs. There is a consistent trend of lower TKE in the shear-thinning rheology compared to the Newtonian. The results suggest that using a Newtonian rheology could possibly underpredict the effects of TKE on RBCs in particular at low Re. This could result in different predictions of blood trauma for medical devices. For understanding the potential TKE effects on RBCs specifically for haemolysis, the total energy spectrum should be considered, but first, high quality computations are needed.

When comparing the instantaneous velocity and vorticity fields in Figures 9 and 10, we observe some distinct features which are analogous to the flow fields present in stenoses at transitional and high Re flows. Coherent vortical structures which develop through increasing $R e$ become evident at 
$R e=3000$, with separation of the shear layer and extension of vortex shedding through the domain. No exact qualitative differences between the Newtonian and shear-thinning rheologies can be made from the velocity and vorticty flow fields, for determination of $R e_{c r}$, but it can be appreciated that the flow field varies spatially considerably making determination of $R e_{c r}$ difficult.

\subsection{Definition of Reynolds Number on Shear-Thinning Rheology}

Instantaneous dynamic viscosity plots in Figure 16 show the spatial distribution of viscosity within the domain. The primary recirculating flow region has low shear and the dynamic viscosity is the highest as indicated by Figure 8 below $=1000$. The shear-thinning model exhibits shorter recirculation zone length compared to the Newtonian model. As the Reynolds number increases, we see a decrease in the dynamic viscosity in this flow region; however, small regions of high dynamic viscosity are still evident in the turbulent Reynolds number $R e=6000$ and $R e=7000$.

As discussed by Khan et al. [18], the definition of a Reynolds number is ultimately dependent on the characterisation of viscosity. They suggested five viscosity measures which the Reynolds number could be based upon: volume average, mean centreline, mean wall, zero-shear and infinite shear viscosity [18]. For our simulations, the infinite shear viscosity $\mu_{\infty}$ was used as the constant viscosity for our Newtonian blood model, a value of $3.5 \mathrm{mPa}$.s. To explore the effects of viscosity definition, the spanwise spatially averaged dynamic viscosity was determined for each Reynolds number. Using this new definition of viscosity for each Reynolds number, the viscosity vs. Reynolds number is plotted in Figure 17. These results show that using a spatially averaged viscosity reduces the Reynolds number, which in turn would change the critical Reynolds number $R e_{c r}$.

By using $R e_{m o d}$, the analysis of $R e_{c r}$ which used the recirculation zone length, turbulence intensity and turbulent kinetic energy changes. For each of these parameters, using $R e_{\text {mod }}$ suggests transition to turbulence occurs at a lower Re with the shear-thinning rheology as compared with the Newtonian: with recirculation zone length (Figure 18) 857 versus 1200; with mean turbulence intensity (Figure 19) 1250 versus 1600; and with mean turbulent kinetic energy (Figure 20) 1048 versus 1400. This analysis shows that $R e_{\text {mod }}$ cannot predict differences in $R e_{c r}$, for this non-Newtonian flow over a BFS, found using the different methods.

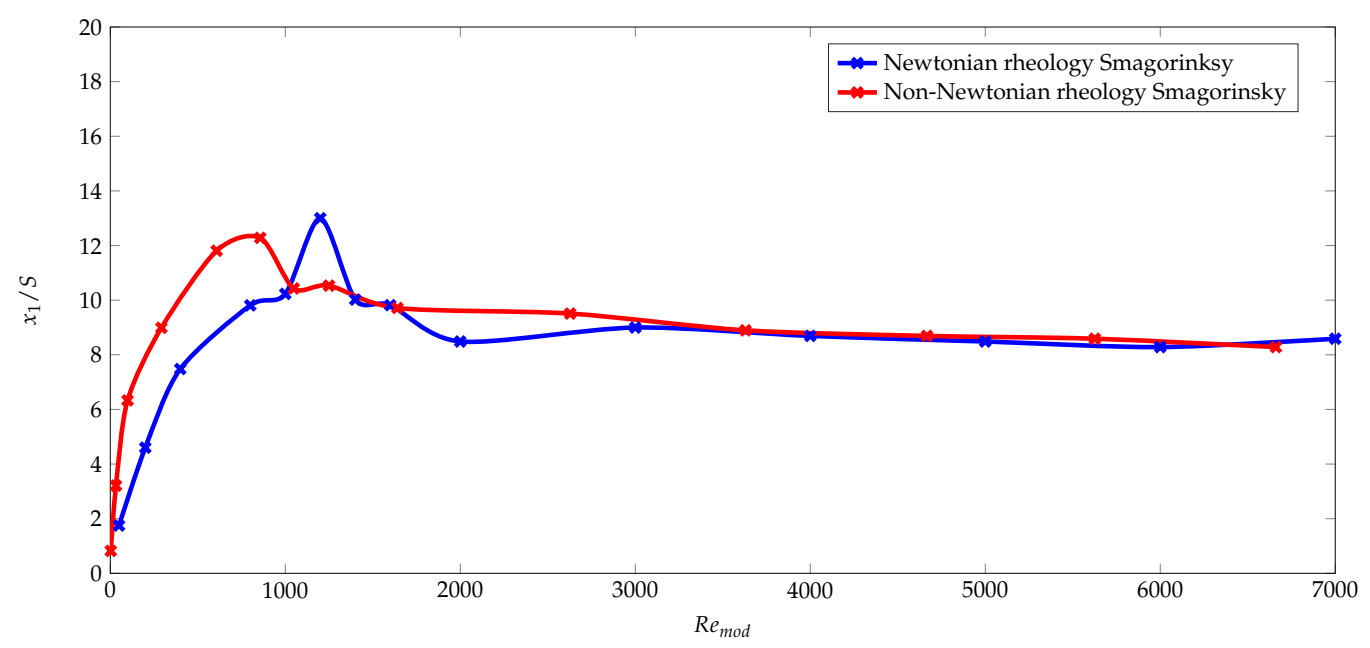

Figure 18. $x_{1} / S$ of Newtonian and shear-thinning blood rheology plotted against modified Reynolds number $R e_{\text {mod }}$. 


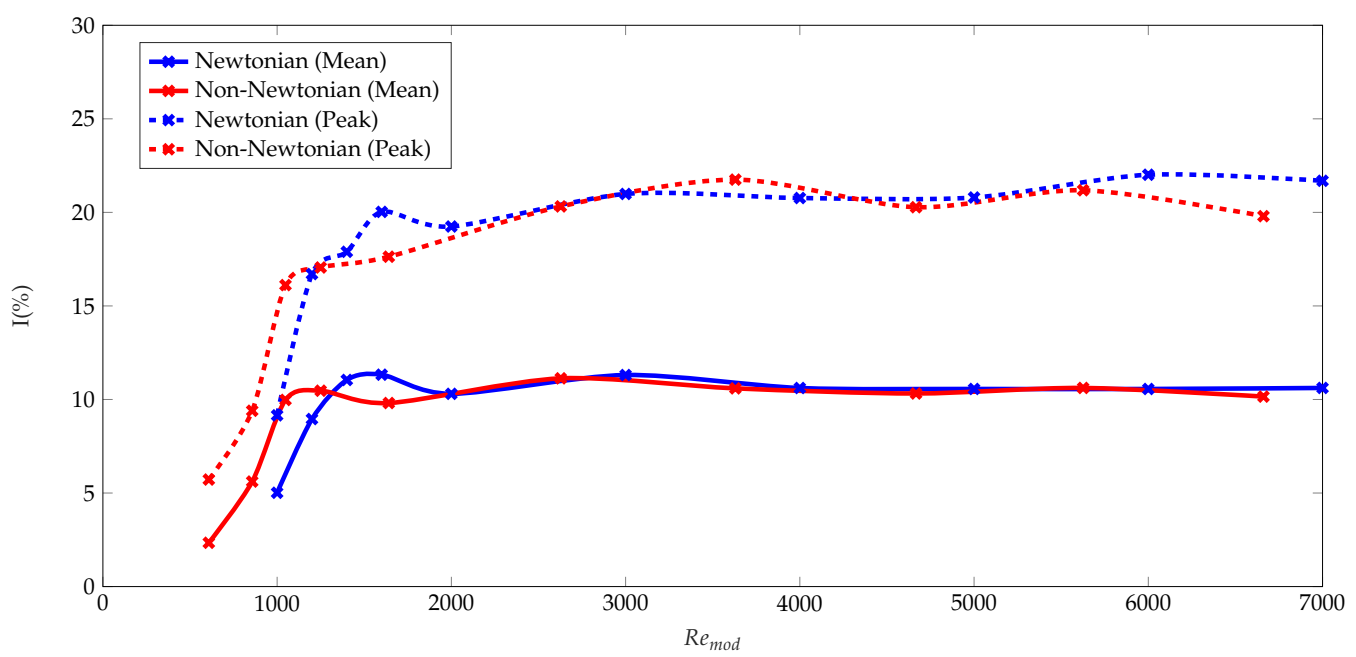

Figure 19. Turbulence intensity of Newtonian and shear-thinning blood rheology plotted against modified Reynolds number $R e_{\text {mod }}$.

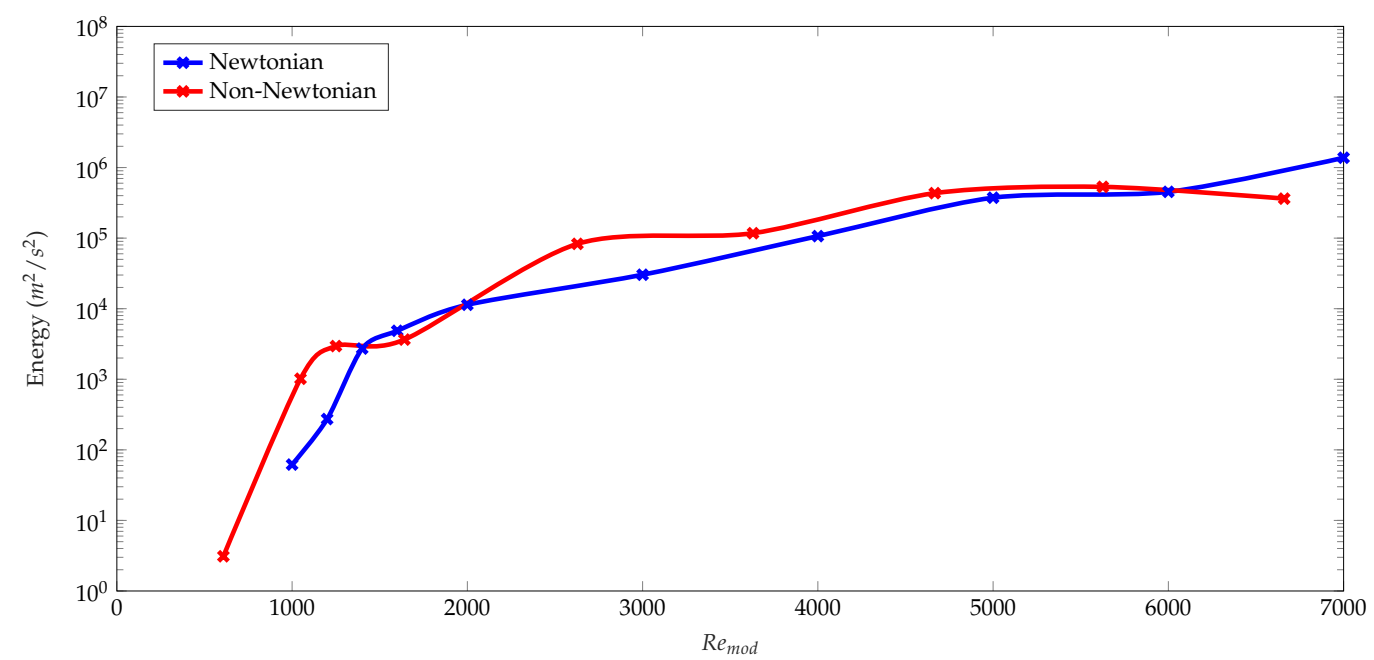

Figure 20. Mean energy frequency of Newtonian and shear-thinning blood rheology plotted against modified Reynolds number $R e_{\text {mod }}$.

\subsection{Limitations and Future Perspectives}

The use of high fidelity computational methods often poses limitations due to the time and resources required. Reynolds numbers were investigated over a wide range from the low Reynolds number limit to fully turbulent flow. However, exploring the onset of transition in our case requires small increments of $R e$ to accurately predict $R e_{c r}$. For URANS, this may be easier as the computational resources are less demanding compared to that of LES, but, as the results show, they fail to predict any transitional flow behaviour. LES calculations in smaller increments from $R e=1000-2500$ may provide more valuable information for characterising laminar-turbulent transition between the two rheology models. As mentioned previously, subgrid scale models vary when predicting transition to turbulence (location and Reynolds number), we have just restricted ourselves to the most common subgrid scale model-the Smagorinsky model. A dynamic Smagorinsky model may have been more suitable for the work due to the importance of transitional flow dynamics. Sayadi and Moin [55] noted that, for flow over a flat plate, the natural transition occurs better with this model as disturbances in the flow are allowed to grow naturally. This is because the turbulent viscosity is not introduced immediately and does not provide artificial transition. 
Only one of the many rheological models to describe blood has been studied here. The influence of other rheology models and its relation to laminar-turbulent transition has not been investigated, but may provide a wider scatter of results on the determination of $R e_{c r}$. Incorporation of yield stress and thixotropic behaviour of blood within the rheology model should provide a more realistic effect of RBCs behaviour especially at transitional $R e$. Viscoelasticity of RBCs have been proposed as having a damping effect [56] and again, in terms of the energy, the transfer is passed down through RBCs and dissipated through mechanical stresses. Numerically to verify these ideas, blood would need to be considered at the microscale, which becomes computationally expensive. The implementation of the rheology models used existing experimental rheological data on whole blood. Curve fitting of the common shear-thinning rheology models; Cross, Bird, Carreau and Yasuda relies on determination of parameters. Gallagher et al. [57] found that the most common shear-thinning rheology models for blood had wide spectrum of uncertainty when fitting parameters to experimental data and an existing problem of parameter identifiability. This can ultimately affect the flow profiles, particularly important in complex flow fields such as those experienced in VADs and stenotic flows.

Assuming no pulsatility exists in the flow is a limitation that could be explored further. Choi and Barakat [28] found that the periodic changes in inlet conditions had a large effect on the formation of recirculation zones between the two rheologies at low Re. However, the pulsatile effect has not been explored at transitional $R e$ and may play a significant role in speculations of delays in transition to turbulence. This will become particularly important when we consider the flows in which these behaviours are observed i.e., mechanical circulatory support devices, stents and stenosed vessels. Unquestionably, one of the main limitations of this study is the simplification of blood simulated as a single phase fluid. The computational resources required to solve a high fidelity, dense suspension of RBCs in transitional and turbulent flow regimes would be extremely high.

\section{Conclusions}

The continued innovation of blood contacting medical devices is reliant on accurate numerical modelling of blood flow. Since these devices, which include valves, stents and artificial hearts, operate in the transitional regime, understanding how the rheological properties of blood impact on transitional flow is vital.

This paper presents the most comprehensive numerical study to-date of laminar-turbulent transition over a backward facing step for Newtonian fluids, and is the first such study for shear thinning rheology. Three-dimensional flow was simulated for $50 \leq R e \leq 7000$ with two turbulence modelling methods: URANS using the $k-\omega$ SST model, and LES using the Smagorinsky SGS model. Use of a mapped boundary condition created an infinitely long inlet allowing both the mean velocity profile, and correct turbulent velocity fluctuations, to develop naturally.

Only LES could predict the correct trends in the recirculation zone length across all Re. Compared to existing experimental data on variation in the recirculation zone length with $R e$ [29], the Newtonian fluid had the correct critical $\operatorname{Re}\left(R e_{c r}=1200\right)$. The recirculation zone lengths differed with $x_{1} / S$ in laminar flow being $22 \%$ shorter in the shear-thinning model, compared to the Newtonian model, which matched existing experimental data [28].

Comparison of the laminar-turbulent transition for shear-thinning and Newtonian rheologies revealed a complex picture. Several methods were used to analyse transition and those that used instantaneous velocities found a delay in the transition with the shear-thinning fluid compared to the Newtonian fluid. Determination of $R e_{c r}$ by examining the velocity signals through time showed that $R e_{c r}$ for the Newtonian model was 1600, while $R e_{c r}$ for the shear-thinning model was 2000 . This delay is of the same magnitude as that found in published experimental data [16]. More details on the transitions were found by examining the turbulence intensities: the Newtonian rheology had higher turbulence intensities at lower Reynolds numbers as compared with the non-Newtonian rheology.

In contrast, when analysing the instantaneous velocities, the mean flow revealed no such delay; according to the variation in recirculation zone lengths with Re both the Newtonian and shear-thinning 
fluids transitioned at the same $R e_{c r}(R e=1200)$. Use of a modified Reynolds number, based on the spatially averaged viscosity across the whole flow domain, could explain some, but not all, of the differences in transition between Newtonian and shear-thinning rheologies.

In summary, the increased viscosity at low shear rates in the shear-thinning fluid damps out turbulent fluctuations and so delays transition to turbulence assessed from velocity fluctuations. This explains the delay observed in published experimental studies. However, this delay is not the complete picture: the characteristics of the mean flow field are not altered enough to delay the transition according to changes in the primary recirculation zone length. To fully capture transitional blood flow, it is essential to explicitly model both the shear-thinning rheology and the turbulent eddies. Doing so will enable accurate models of the flow through blood contacting cardiovascular devices; these models are essential for improving the design of devices.

Author Contributions: Conceptualization, N.S.K., K.H.F. and A.N.C.; Methodology, N.S.K. and K.H.F.; formal analysis, N.S.K., K.H.F. and A.N.C.; writing-original draft preparation, N.S.K.; writing-review and editing, K.H.F., A.N.C. and H.S.G.; supervision, K.H.F., A.N.C. and H.S.G. All authors have read and agreed to the published version of the manuscript.

Funding: This research was funded by an EPSRC DTP awarded to N.S.K.

Acknowledgments: This research made use of the Balena High Performance Computing (HPC) Service at the University of Bath and Cirrus UK National Tier-2 HPC Service at EPCC (http:/ / www.cirrus.ac.uk) funded by the University of Edinburgh and EPSRC (EP/P020267/1).

Conflicts of Interest: The authors declare no conflict of interest.

\section{Abbreviations}

The following abbreviations are used in this manuscript:

$\begin{array}{ll}\text { LES } & \text { Large Eddy Simulation } \\ \text { URANS } & \text { Unsteady Reynolds averaged Navier Stokes } \\ \text { DNS } & \text { Direct numerical simulation } \\ \text { SGS } & \text { Subgrid scale } \\ \text { GS } & \text { Grid scale } \\ \text { TKE } & \text { Turbulent kinetic energy } \\ \text { MHV } & \text { Mechanical heart valve } \\ \text { VAD } & \text { Ventricular assist device } \\ \text { CFD } & \text { Computational fluid dynamics } \\ \text { BFS } & \text { Backward facing step } \\ \text { RMS } & \text { Root mean square } \\ \text { TI } & \text { Turbulence intensity } \\ \text { RBC } & \text { Red blood cell } \\ R e & \text { Reynolds number } \\ R e_{c r} & \text { Critical Reynolds number } \\ R e_{m o d} & \text { Modified Reynolds number }\end{array}$

\section{References}

1. Dewey, C.F.; Bussolari, S.R.; Gimbrone, M.A.; Davies, P.F. The Dynamic Response of Vascular Endothelial Cells to Fluid Shear Stress. J. Biomech. Eng. 1981, 103, 177. [CrossRef]

2. Chiu, J.J.; Usami, S.; Chien, S. Vascular endothelial responses to altered shear stress: Pathologic implications for atherosclerosis. Ann. Med. 2009, 41, 19-28. [CrossRef] [PubMed]

3. Einav, S.; Bluestein, D. Dynamics of blood flow and platelet transport in pathological vessels. Ann. N. Y. Acad. Sci. 2004, 1015, 351-366. [CrossRef] [PubMed]

4. Stein, P.D.; Sabbah, H.N. Turbulent Blood-Flow in Ascending Aorta of Humans with Normal and Diseased Aortic Valves. Circ. Res. 1976, 39, 58-65. [CrossRef] [PubMed] 
5. Ha, H.; Ziegler, M.; Welander, M.; Bjarnegård, N.; Carlhäll, C.J.; Lindenberger, M.; Länne, T.; Ebbers, T.; Dyverfeldt, P. Age-related vascular changes affect turbulence in aortic blood flow. Front. Physiol. 2018, 9, 36. [CrossRef]

6. Kameneva, M.V.; Burgreen, G.W.; Kono, K.; Repko, B.; Antaki, J.F.; Umezu, M. Effects of Turbulent Stresses upon Mechanical Hemolysis: Experimental and Computational Analysis. ASAIO J. 2004, 50, 418-423. [CrossRef]

7. Luckraz, H.; Woods, M.; Large, S.R. In addition, hemolysis goes on: Ventricular assist device in combination with veno-venous hemofiltration. Ann. Thorac. Surg. 2002, 73, 546-548. [CrossRef]

8. Chien, S.; Usami, S.; Taylor, H.M.; Lundberg, J.L.; Gregersen, M.I. Effects of hematocrit and plasma proteins on human blood rheology at low shear rates. J. Appl. Physiol. 1966, 21, 81-87. [CrossRef]

9. Goldsmith, H.L. The microrheology of red blood cell suspensions. J. Gen. Physiol. 1968, 52, 5-28. [CrossRef]

10. Dintenfass, L. Thixotropy of blood and proneness to thrombus formation. J. Am. Heart Res. 1962, XI, $233-239$. [CrossRef]

11. Merrill, E.W.; Gilliland, E.R.; Cokelet, G.; Shin, H.; Britten, A.; Wells, R.E. Rheology of Human Blood, near and at Zero Flow: Effects of Temperature and Hematocrit Level. Biophys. J. 1963, 3, 199-213. [CrossRef]

12. Thurston, G. Viscoelasticity of Human Blood. Biophys. J. 1972, 12, 1205-1217. 3495(72)86156-3. [CrossRef]

13. Chien, S.; King, R.G.; Skalak, R.; Usami, S.; Copley, A.L. Viscoelastic Properties of Human Blood and Red Cell Suspensions. Biorheology 1975, 12, 341-346. [CrossRef] [PubMed]

14. Coulter, N.A., Jr.; Pappenheimer, J.R. Development of turbulence in flowing blood. Am. J. Physiol. 1949, 159, 401-408. [CrossRef]

15. Nerem, R.M.; Seed, W.A.; Wood, N.B. An experimental study of the velocity distribution and transition to turbulence in the aorta. J. Fluid Mech. 1972, 52, 137-161. [CrossRef]

16. Biswas, D.; Casey, D.M.; Crowder, D.C.; Steinman, D.A.; Yun, Y.H.; Loth, F. Characterization of Transition to Turbulence for Blood in a Straight Pipe Under Steady Flow Conditions. J. Biomech. Eng. 2016, 138, 071001. [CrossRef]

17. Sherwin, S.J.; Blackburn, H.M. Three-dimensional instabilities and transition of steady and pulsatile axisymmetric stenotic flows. J. Fluid Mech. 2005, 533, 297-327. [CrossRef]

18. Khan, M.O.; Valen-Sendstad, K.; Steinman, D.A. Direct Numerical Simulation of Laminar-Turbulent Transition in a Non-Axisymmetric Stenosis Model for Newtonian vs. Shear-Thinning Non-Newtonian Rheologies. Flow Turbul. Combust. 2018, 102, 43-72. [CrossRef]

19. Escudier, M.P.; Poole, R.J.; Presti, F.; Dales, C.; Nouar, C.; Desaubry, C.; Graham, L.; Pullum, L. Observations of asymmetrical flow behaviour in transitional pipe flow of yield-stress and other shear-thinning liquids. J. Non-Newton. Fluid Mech. 2005, 127, 143-155. [CrossRef]

20. Güzel, B.; Burghelea, T.; Frigaard, I.A.; Martinez, D.M. Observation of laminar-turbulent transition of a yield stress fluid in Hagen-Poiseuille flow. J. Fluid Mech. 2009, 627, 97-128. [CrossRef]

21. Bahrani, S.A.; Nouar, C. Intermittency in the transition to turbulence for a shear-thinning fluid in hagen-poiseuille flow. J. Appl. Fluid Mech. 2014, 7, 1-6.

22. Peixinho, J.; Nouar, C.; Desaubry, C.; Théron, B. Laminar transitional and turbulent flow of yield stress fluid in a pipe. J. Non-Newton. Fluid Mech. 2005, 128, 172-184. [CrossRef]

23. Escudier, M.P.; Presti, F.; Smith, S. Drag reduction in the turbulent pipe flow of polymers. J. Non-Newton. Fluid Mech. 1998, 81, 197-213. [CrossRef]

24. Pozarlik, A.K.; Kok, J.B.W. Numerical Simulation of a Turbulent Flow Over a Backward Facing Step with Heated Wall: Effect of Pulsating Velocity and Oscillating Wall. J. Therm. Sci. Eng. Appl. 2012, 4, 041005. [CrossRef]

25. Pearce, B.W.; Brandner, P.A.; Foster, S.J. Ventilated cavity flow over a backward-facing step. J. Phys. Conf. Ser. 2015, 656, 012164. [CrossRef]

26. Truskey, G.A.; Barber, K.M.; Robey, T.C.; Olivier, L.A.; Combs, M.P. Characterization of a Sudden Expansion Flow Chamber to Study the Response of Endothelium to Flow Recirculation. J. Biomech. Eng. 1995, 117, 203-210. [CrossRef] [PubMed]

27. Gijsen, F.J.H.; Van De Vosse, F.N.; Janssen, J.D. Wall shear stress in backward-facing step flow of a red blood cell suspension. Biorheology 1998, 35, 263-279. [CrossRef]

28. Choi, H.W.; Barakat, A.I. Numerical study of the impact of non-Newtonian blood behavior on flow over a two-dimensional backward facing step. Biorheology 2005, 42, 493-509. 
29. Armaly, B.F.; Durst, F.; Pereira, J.C.F.; Schönung, B. Experimental and theoretical investigation of backward-facing step flow. J. Fluid Mech. 1983, 127, 473. [CrossRef]

30. Schäfer, F.; Breuer, M.; Durst, F. The dynamics of the transitional flow over a backward-facing step. J. Fluid Mech. 2009, 623, 85-119. [CrossRef]

31. Rani, H.P.; Sheu, T.W.; Tsai, E.S. Eddy structures in a transitional backward-facing step flow. J. Fluid Mech. 2007, 588, 43-58. [CrossRef]

32. Kaiktsis, L.; Karniadakis, G.M.; Orszag, S.A. Onset of three-dimensionality, equibria and early transition in flow over a backward-facing step. J. Fluid Mech. 1991, 231, 501-528. [CrossRef]

33. Le, H.; Moin, P.; Kim, J. Direct Numerical Simulation of Turbulent Flow over a Backward-Facing Step. J. Fluid Mech. 1997, 330, 349-374. [CrossRef]

34. DePaola, N.; Gimbrone, M.A.; Davies, P.F.; Dewey, C.F. Vascular endothelium responds to fluid shear stress gradients [published erratum appears in Arterioscler Thromb 1993 Mar;13(3):465]. Arterioscler. Thromb. Vasc. Biol. 1992, 12, 1254-1257. [CrossRef] [PubMed]

35. Driver, D.M.; Seegmiller, H.L. Features of a reattaching turbulent shear layer in divergent channelflow. AIAA J. 1985, 23, 163-171. [CrossRef]

36. Poole, R.J.; Escudier, M.P. Turbulent flow of non-Newtonian liquids over a backward-facing step Part I. A thixotropic and shear-thinning liquid. J. Non-Newton. Fluid Mech. 2003, 109, 177-191. [CrossRef]

37. Poole, R.J.; Escudier, M.P. Turbulent flow of non-Newtonian liquids over a backward-facing step Part II. Viscoelastic and shear-thinning liquids. J. Non-Newton. Fluid Mech. 2003, 109, 193-230. [CrossRef]

38. Barri, M.; Khoury, G.K.E.; Andersson, H.I.; Pettersen, B. DNS of backward-facing step flow with fully turbulent inflow. Int. J. Numer. Methods Fluids 2009. [CrossRef]

39. Kopera, M.A.; Kerr, R.M.; Blackburn, H.M.; Barkley, D. Direct numerical simulation of turbulent flow over a backward-facing step. J. Fluid Mech. 2014, in press.

40. Weller, H.G.; Tabor, G.; Jasak, H.; Fureby, C. A tensorial approach to computational continuum mechanics using object-oriented techniques. Comput. Phys. 1998, 12, 620-631. [CrossRef]

41. Menter, F.R. Two-equation eddy-viscosity turbulence models for engineering applications. AIAA J. 1994, 32, 1598-1605. [CrossRef]

42. Robertson, A.M.; Kameneva, M.V. Hemorheology. In Hemodynamical Flows. Oberwolfach Seminars; Birkhuser: Basel, Switzerland, 2008; Volume 37, pp. 63-120.

43. Cho, Y.I.; Kensey, K.R. Effects of the non-Newtonian viscosity of blood on flows in a diseased arterial vessel. Part 1: Steady flows. Biorheology 1991, 28, 241-262. [CrossRef] [PubMed]

44. Balena HPC Cluster. Available Online: https://www.bath.ac.uk/corporate-information/balena-hpccluster/ (accessed on 21 April 2020).

45. Cirrus Powered by EPCC. Available online: http://www.cirrus.ac.uk/ (accessed on 21 April 2020).

46. Braunmüller, S.; Schmid, L.; Sackmann, E.; Franke, T. Hydrodynamic deformation reveals two coupled modes/time scales of red blood cell relaxation. Soft Matter 2012, 8, 11240-11248. [CrossRef]

47. Capoccia, M.; Bowles, C.T.; Sabashnikov, A.; Simon, A. Recurrent Early Thrombus Formation in HeartMate II Left Ventricular Assist Device. J. Investig. Med. High Impact Case Rep. 2013, 1. [CrossRef]

48. Hasin, T.; Deo, S.; Maleszewski, J.J.; Topilsky, Y.; Edwards, B.S.; Pereira, N.L.; Stulak, J.M.; Joyce, L.; Daly, R.; Kushwaha, S.S.; et al. The Role of Medical Management for Acute Intravascular Hemolysis in Patients Supported on Axial Flow LVAD. ASAIO J. 2014, 60, 9-14. [CrossRef] [PubMed]

49. Neofytou, P.; Drikakis, D. Effects of blood models on flows through a stenosis. Int. J. Numer. Methods Fluids 2003, 43, 597-635. [CrossRef]

50. Pal, A.; Anupindi, K.; Delorme, Y.; Ghaisas, N.; Shetty, D.A.; Frankel, S.H. Large Eddy Simulation of Transitional Flow in an Idealized Stenotic Blood Vessel: Evaluation of Subgrid Scale Models. J. Biomech. Eng. 2014, 136, 071009. [CrossRef] [PubMed]

51. Varghese, S.S.; Frankel, S.H.; Fischer, P.F. Modeling Transition to Turbulence in Eccentric Stenotic Flows. J. Biomech. Eng. 2008, 130, 014503. [CrossRef]

52. Tan, F.P.P. Comparison of LES of Steady Transitional Flow in an Idealized Stenosed Axisymmetric Artery Model With a RANS Transitional Model. J. Biomech. Eng. 2011, 133, 051001. [CrossRef]

53. Premnath, K.N.; Pattison, M.J.; Banerjee, S. An Investigation of the Lattice Boltzmann Method for Large Eddy Simulation of Complex Turbulent Separated Flow. J. Fluids Eng. 2013, 135, 051401. [CrossRef] 
54. Rahgozar, S.; Rival, D.E. On turbulence decay of a shear-thinning fluid. Phys. Fluids 2017, $29,123101$. [CrossRef]

55. Sayadi, T.; Moin, P. Predicting natural transition using large eddy simulation. In Center for Turbulence Research Annual Research Briefs; Stanford University: Stanford, CA, USA, 2011

56. Han, S.I.; Marseille, O.; Gehlen, C.; Blümich, B. Rheology of Blood by NMR. J. Magn. Reson. 2001, 152, 87-94. [CrossRef] [PubMed]

57. Gallagher, M.; Wain, R.; Dari, S.; Whitty, J.; Smith, D. Non-identifiability of parameters for a class of shear-thinning rheological models, with implications for haematological fluid dynamics. J. Biomech. 2019, 85, 230-238. [CrossRef] [PubMed]

(C) 2020 by the authors. Licensee MDPI, Basel, Switzerland. This article is an open access article distributed under the terms and conditions of the Creative Commons Attribution (CC BY) license (http:/ / creativecommons.org/licenses/by/4.0/). 